\title{
2020 update on the renin-angiotensin-aldosterone system in pediatric kidney disease and its interactions with coronavirus
}

\author{
Ana Cristina Simões e Silva ${ }^{1,2}$ (D) Katharina Lanza ${ }^{1}$ - Vitória Andrade Palmeira ${ }^{1}$ - Larissa Braga Costa ${ }^{1}$ \\ Joseph T. Flynn ${ }^{3}$
}

Received: 15 June 2020 / Revised: 12 August 2020 / Accepted: 3 September 2020 / Published online: 29 September 2020 (C) IPNA 2020

\begin{abstract}
The last decade was crucial for our understanding of the renin-angiotensin-aldosterone system (RAAS) as a two-axis, counterregulatory system, divided into the classical axis, formed by angiotensin-converting enzyme (ACE), angiotensin II (Ang II), and the angiotensin type 1 receptor (AT1R), and the alternative axis comprising angiotensin-converting enzyme 2 (ACE2), angiotensin-(1-7) (Ang-(1-7)), and the Mas receptor. Breakthrough discoveries also took place, with other RAAS endopeptides being described, including alamandine and angiotensin A. In this review, we characterize the two RAAS axes and the role of their components in pediatric kidney diseases, including childhood hypertension (HTN), pediatric glomerular diseases, congenital abnormalities of the kidney and urinary tract (CAKUT), and chronic kidney disease (CKD). We also present recent findings on potential interactions between the novel coronavirus, SARS-CoV-2, and components of the RAAS, as well as potential implications of coronavirus disease 2019 (COVID-19) for pediatric kidney diseases.
\end{abstract}

Keywords Ang II · Ang-(1-7) · ACE · ACE2 $\cdot$ Chronic kidney disease $\cdot$ Hypertension $\cdot$ COVID-19 $\cdot$ Children

\section{Introduction and history}

The renin-angiotensin-aldosterone system (RAAS) was first conceived as a single-arm hormonal axis centered on the biological functions of Angiotensin II (Ang II). The RAAS has subsequently grown in scientific relevance due to its multiplicity of physiological interactions. Nowadays, the RAAS is considered a two-arm, counter-regulatory system, with the most important peptides being Ang II and angiotensin-(1-7) (Ang-(1-7)) [1]. Figure 1 shows the RAAS cascade. The present knowledge about RAAS, however, has gradually developed over the years.

Ana Cristina Simões e Silva

acssilva@hotmail.com

1 Interdisciplinary Laboratory of Medical Investigation, Faculty of Medicine, Federal University of Minas Gerais (UFMG), Avenida Alfredo Balena, 190, 2nd floor, Room \# 281, Belo Horizonte, MG 30130-100, Brazil

2 Pediatric Nephrology Unit, Department of Pediatrics, Faculty of Medicine, UFMG, Belo Horizonte, Brazil

3 Pediatric Nephrology, Seattle Children's Hospital, University of Washington School of Medicine, Seattle, WA 98105, USA
The concept of the RAAS classical axis started with the discovery of vasoactive substances related to left ventricular hypertrophy [2]. The primary RAAS fragments were described after several experimental studies using arterial hypertension models as a result of renal ischemia [2]. The first fragment identified by Tigerstedt and Bergman was the aspartyl-type acid protease renin. The formation of Ang II by means of the removal of two amino acids from angiotensin I (Ang I) by the angiotensin-converting enzyme (ACE), however, was not described until 1940 by groups in Argentina and the USA [2]. Ang II, hence, was determined as a potent vasoconstrictor that elevates arterial blood pressure (BP) by increasing vascular resistance. Further characterization occurred in the 1970s, as the binding mechanism of Ang II to the membrane-binding sites, later named as angiotensin II receptor types 1 and 2 (AT1R and AT2R), was clarified after studies based on RAAS nonspecific antagonism with saralasin [3]. Hence, it was established that Ang II contributes to sodium/potassium balance, body fluid volume and arterial pressure homeostasis by stimulating vasoconstriction, sodium reabsorption, and aldosterone release [4]. The complementary biological functions of the ACE/Ang II/AT1R axis included the discovery of new roles for Ang II, including its proinflammatory properties, by several research groups [5]. 


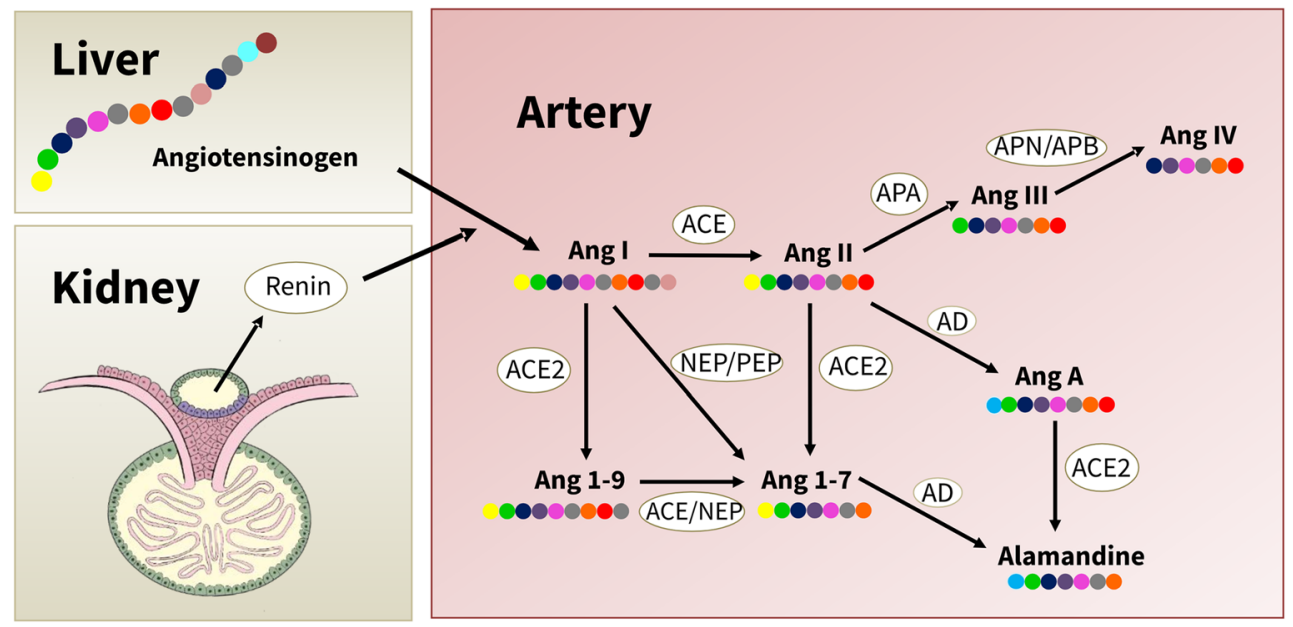

Fig. 1 Then renin-angiotensin system cascade. Legend: The liver produces angiotensinogen (AGT), a 14-amino-acid peptide, which is secreted in sinusoidal capillaries. The 485-amino-acid (61 kDa) human AGT glycoprotein contains a signal peptide that is removed co-translationally to yield the 452-amino-acid substrate of renin resulting in 14 amino acids plus 438 amino acids. Renin, an enzyme produced by the juxtaglomerular apparatus of the kidney, is also secreted in the circulation. In the blood stream, angiotensinogen is cleaved by renin into Ang I, which can also be cleaved by ACE2, producing Ang-1-9; by NEP or PEP, producing Ang(1-7); and by ACE, producing Ang II. From that point, Ang II can also be cleaved by ACE2 and produce Ang-(1-7) or it can be cleaved by APA,

The first evidence of the alternative RAAS axis was established in 1988, when Santos et al. [6] described the formation of Ang-(1-7) by an ACE-independent pathway. In the same year, Schiavone et al. [7] reported that Ang-(1-7) is equipotent to Ang II in releasing vasopressin (AVP) from the rat hypothalamo-neurohypophysial system (HNS) in vitro. A year later, Campagnole-Santos et al. [8] first described the biological actions of Ang-(1-7) in vivo, including several vasodilatory effects related to the release of nitric oxide and prostaglandins, therefore antagonizing the well-established classical RAAS arm. In 2000, Tipnis et al. [9] and Donoghue et al. [10] simultaneously discovered the production of Ang-(17) by means of the removal of a phenylalanine from the Ang II, catalyzed by the carboxypeptidase angiotensin-converting enzyme 2 (ACE2). More importantly, in 2003, the G proteincoupled Mas receptor (MasR) was identified as the specific binding-site for Ang-(1-7) [11]. Similar to the classical axis, the ACE2/Ang-(1-7)/MasR axis also has functions beyond the kidney and cardiovascular systems, including inhibition of cell growth and anti-inflammatory actions [12]. When the molecular basis for the physiological function of the alternative RAAS axis was clearly established, the system was conceived as composed of two main axes with opposite local and systemic effects [1]. Figure 2 shows the opposite actions of both RAAS axes.

The diversity of the RAAS, however, goes far beyond these two axes. New hormone fragments and functions continue to be discovered, including pro-renin, alamandine, producing Ang III. Ang II can still have its first amino acid replaced, forming Ang A, which can be cleaved by ACE2 into alamandine. This heptapeptide alamandine can also be formed by Ang-(1-7) due to replacement of one amino acid. Ang III can be cleaved by APN and form Ang IV. Ang I, angiotensin I; Ang II, angiotensin II; Ang III, angiotensin III; Ang IV, angiotensin IV; Ang 1-9, angiotensin (1-9); Ang 1-7, angiotensin (1-7); Ang A, angiotensin A; ACE2, angiotensin-converting Enzyme; NEP, neutral-endopeptidase; ACE, angiotensin-converting enzyme; $\mathrm{AD}$, aspartate decarboxylase; APA, aminopeptidase A; APN, aminopeptidase N; APB, aminopeptidase B

angiotensin-(1-9) and angiotensin IV [1]. Given the expanded understanding of the RAAS, this review aims to summarize the biochemical and physiological roles of the RAAS, as well as to discuss the involvement of this system in pediatric kidney diseases and related conditions. Furthermore, we also present recent findings on the potential interactions between the novel coronavirus, SARS-CoV-2, and RAAS components and some potential implications of coronavirus disease 2019 (COVID-19) for pediatric kidney diseases.

\section{Current understanding of the RAAS}

\section{The classical RAAS axis}

The RAAS is well-known for its major role in BP control and fluid balance [13]. Its endocrine (tissue-to-tissue), paracrine (cell-to-cell), and intracrine (intracellular/nuclear) actions are crucial for cardiovascular, kidney, immune, and neural homeostasis [14]. Metabolic pathways of the classical RAAS axis start with the conversion of angiotensinogen (Agt) into angiotensin I (Ang I) by renin. The subsequent cascade of events depends on the activity of the two angiotensinconverting enzymes to either form Ang II or Ang-(1-7), the effector peptides of the RAAS [14] (Fig. 1).

The Agt gene is located on chromosome 1 and leads to the expression of a 14 amino acid peptide (Asp-Arg-Val-TyrIle-His-Pro-Phe-His-Leu-Leu-Val-Tyr-Ser) that is 


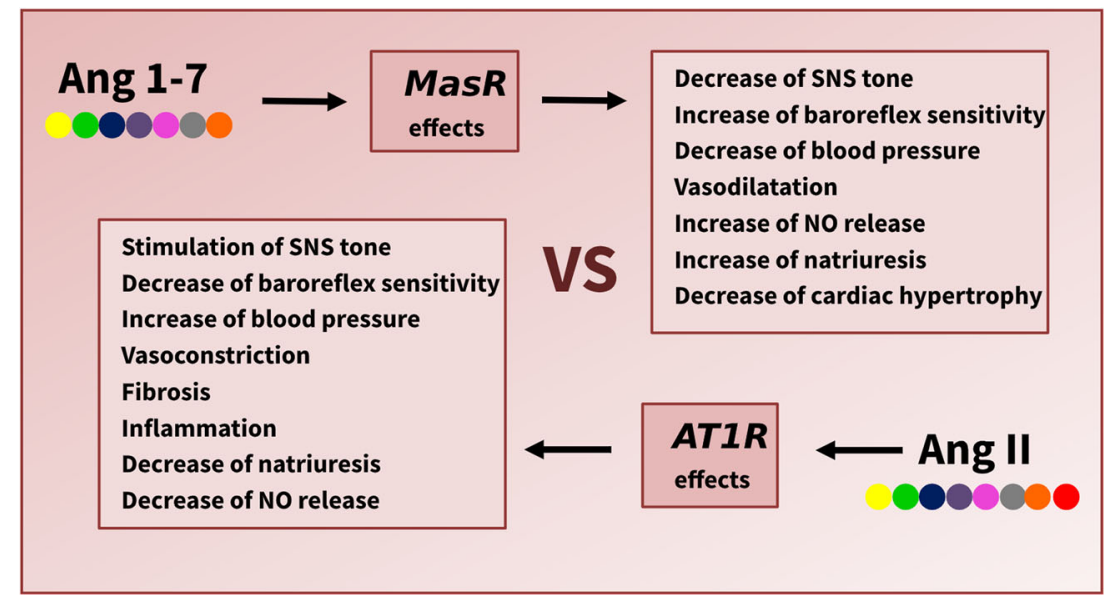

Fig. 2 Opposite actions of classical and alternative RAS axes. Legend: Ang II binds to AT1 receptors and produces the traditional actions of RAS classical axis, including stimulation of SNS tone, of vasoconstriction, of inflammation, and of fibrosis and decrease of baroreflex sensitivity, of natriuresis, and of $\mathrm{NO}$ release. The alternative axis, however, is activated mostly due to Ang-(1-7) binding to Mas

primarily synthesized by hepatocytes. However, adipose tissue, brain, spinal cord, heart, kidney, lung, adrenal gland, small and large intestine, stomach, spleen, ovaries, and vascular endothelium are also capable of producing Agt [15]. Once synthesized, Agt is released into the bloodstream and has a $5-\mathrm{h}$ half-life [16]. Agt is the only substrate of renin. Although renin is the main enzyme that converts Agt into Ang I, this conversion may also occur by the enzymes chymase; tonin; cathepsins A, D, and G; proteinase-3; and neutrophil elastase [17]. The physiological roles of these enzymes, however, require further characterization [17].

Renin is an aspartyl protease with two isoforms. The first isoform is expressed in the juxtaglomerular ( $\mathrm{JG}$ ) cells and the collecting duct (CD) and has extracellular functions [5]. Renin expressed in JG cells is secreted as pro-renin (inactive) or renin (active) itself and is capable of catalyzing the production of Ang II, which negatively regulates JG production of the enzyme. On the other hand, renin secreted by the CD into the tubular fluid also produces Ang II, and in turn the octapeptide upregulates $\mathrm{CD}$ production of renin. Both are key rate-limiting steps in determining Ang II levels [5]. Hence, regulation of renin expression and secretion significantly impact overall activity of the RAAS. The main stimuli for renin release include the kidney baroreceptor reflex [18], sodium chloride $(\mathrm{NaCl})$ concentration in the macula densa, and renin microRNA expression and stimulation by other molecular pathways, including nitric oxide, prostaglandins, adenosine, and $\beta 1$-adrenergic receptors [13]. The second isoform of renin is related to the intracellular environment. The pathways and location of this second isoform are as yet not well established, but findings suggest an intra-mitochondrial location and association with increased BP [19]. receptors, promoting counter-regulatory actions, including decrease of SNS tone, of blood pressure, and of cardiac hypertrophy; increase of baroreflex sensitivity, of NO release, and of natriuresis; and stimulation of vasodilatation. Ang 1-7, angiotensin 1-7; Ang II, angiotensin II; MasR, Mas receptor; AT1R, AT1 receptor; SNS, sympathetic nervous system; $\mathrm{NO}$, nitric oxide

Ang I, the product of Agt, is an inactive peptide with a 10 amino acid chain (Asp-Arg-Val-Tyr-Ile-His-Pro-Phe-HisLeu). Cleavage of angiotensinogen also generates a 442 amino acid chain named des-(Ang I)-Agt. This remaining fragment appears to have function in plasma, but its actions on BP lack characterization [20]. Subsequently, in the classical RAAS axis pathway, Ang I is converted into Ang II by ACE, which is a dicarboxypeptidase with four isoforms, generated by alternative splicing of the $A C E$ gene [21]. Regarding ACE isoforms, isoforms 1,2, and 4 are expressed somatically, while isoform 3 is expressed in the testicles [21]. Somatic ACE is an ectoenzyme located on the surface of endothelial cells throughout the body, particularly abundant in lungs, intestine, choroid plexus, placenta, and on brush border membranes of kidney tubular cells. A soluble circulating form of ACE can be produced after the enzymatic cleavage of tissue-bound ACE at its transmembrane domain [22]. ACE has two main substrates, both related to BP homeostasis: Ang I and bradykinin, a peptide with vasodilator and natriuretic properties [23].

Ang II is the central octapeptide (Asp-Arg-Val-Tyr-IleHis-Pro-Phe) of the classical RAAS axis. The biological functions of Ang II take place both in the intra- and extracellular space and are mediated by two cell surface receptors, AT1R and AT2R [22]. The receptors belong to a 7-transmembrane receptor family divided by nonpeptide antagonists' affinity difference; however, AT2R only has 34\% sequence homology with AT1R [24]. Although the AT1R has been described to have two subtypes (AT1a and AT1b) in some animal models [25], only one gene has been found to codify AT1R in the human genome [26]. Physiological responses attributed to Ang II-AT1R binding include stimulation of kidney tubular sodium reabsorption, aldosterone release from the adrenal glomerulosa, smooth muscle cell contraction, and stimulation 
of hypothalamic thirst sensors [27]. The AT1R is expressed in multiple organs involved in the regulation of BP, including the kidney, vasculature, adrenal gland, heart, and both central and peripheral nervous systems. Particularly in the kidneys, AT1R is expressed in vasculature, the juxtaglomerular apparatus (JGA), podocytes, mesangial cells, and tubular epithelial cells [26]. This receptor is part of a Gaphaq-linked signaling pathway involving phospholipase C, inositol triphosphate (IP3), and increased intracellular calcium levels [28]. AT1R has also been linked to Janus kinase, a signal transducer and activator of transcription, and $\beta$-arrestin-dependent pathways, linked to extracellular signal-regulated kinases (ERK) activation [29]. Moreover, AT1R can transactivate the epidermal growth factor receptor [30]. This pathway might contribute to chronic kidney injury and kidney epithelial cell hypertrophy [30].

Once activated, the ACE/Ang II/AT1R axis triggers many systemic and local actions which include (1) increased aldosterone production, (2) stimulation of anti-diuretic hormone (ADH) production [31], (3) activation of sympathetic nervous system (SNS) tone, (4) elevation of BP (5) vasoconstriction, (6) cardiac hypertrophy, (7) fibrosis, (8) inflammation, (9) vascular smooth muscle cell (VSMC) dedifferentiation, (10) reactive oxygen species (ROS) production [32], and (11) tissue injury. On the other hand, activation of the ACE/Ang II/ AT1R axis decreases: (1) parasympathetic nervous system (PSNS) tone, (2) baroreflex sensitivity, (3) nitric oxide (NO) production, and (4) natriuresis. Ang II-AT2R binding has opposite effects from AT1R-mediated activities, including vasodilation and natriuresis. Despite being upregulated by sodium depletion and downregulated by Ang II, PDGF, and EGF, AT2R expression is significantly lower during the lifespan, except in fetal and neonatal life [4].

In the kidney, ACE/Ang II/AT1R axis has synergetic local and systemic actions, both resulting in glomerular hypertension due to preferential vasoconstriction of the efferent arteriole. The systemic actions of Ang II include (1) stimulation of the sympathetic nervous system, causing renal vasoconstriction and increased renal tubular sodium reabsorption, and (2) aldosterone secretion, by stimulating adrenal glomerulosa cells in the early and late steps of the steroid biosynthetic cascade. The intrarenal effects of Ang II are (1) vasoconstriction of efferent arterioles, (2) sodium reabsorption in the kidney tubules, and (3) reduction of kidney medullary blood flow $[33,34]$. The intrarenal stimulation of Ang II synthesis is consistently associated with arterial hypertension and chronic kidney disease (CKD). Indeed, studies point to a key role of Ang II in the development of glomerulosclerosis. Indeed, the deletion of the AT1a receptor in animal models resulted in the attenuation of Ang II-induced hypertension [35]. The expression of AT1R in leukocytes and lymphocytes may also trigger several pathological events, including enhanced inflammation and kidney fibrosis by activation of epidermal growth factors, increasing TGF- $\beta 1$ and NF-KB levels, which leads to collagen I deposition [35].

Ang II effects on cardiac structure and function are well established. In the cardiovascular system, Ang II leads to fibrosis, arrhythmias, endothelial dysfunction, and cardiac remodeling. Ang II infusion was associated with concentric left ventricular (LV) hypertrophy due to proliferation of cardiac myocytes. Despite this observation being contested in in vivo models, LV hypertrophy may also be the result of arterial hypertension, endothelial dysfunction, and perivascular fibrosis [35]. Recent studies suggest a key role of Ang II in activating the epidermal growth factor receptor (EGFR) via A desintegrin and metalloproteinase 17 (ADAM17). ADAM17 expression is enhanced in atherosclerosis, in LV hypertrophy with Ang II infusion, and in vascular neointima after angioplasty [35]. Additionally, deletion of ADAM17 in human VSMC culture prevented cardiac and vascular hypertrophy, as well as perivascular fibrosis [36]. With respect to cardiac remodeling secondary to Ang II-enhanced inflammation, its infusion resulted in elevated TNF- $\alpha$, IL-1 $\beta$, NF-KB, and iNOS levels in the heart, which was successfully suppressed by pentoxifylline, a phosphodiesterase inhibitor [37]. Moreover, Ang II infusion in VSMC culture enhanced Nox2 and Nox 4 activity and consequently induced hypertrophy and fibrosis [38]. Nox2, however, was also linked to enhanced contractile function due to increased $\mathrm{Ca}^{2+}$ uptake [38]. Other possible pathways to Ang II-induced cardiac hypertrophy include $\beta$-arrestin, IP3, and RhoA [35]. All cited remodeling mechanisms might exert a major role in atrial fibrillation (AF) development, the most common arrhythmia. Accordingly, the VALUE and TRIAL studies showed the beneficial effects of AT1R blocking in preventing AF, reinforcing the key role of ACE/Ang II/AT1R axis in cardiac hypertrophy [39].

The deleterious pulmonary actions of Ang II have become more well-known since the recently described beneficial effects of ACE2/Ang-(1-7)/MasR axis in lung tissue. Additionally, this mechanism has recently been associated with the pathophysiology of infection with SARS-CoV-2 [40] (see the discussion below). The role of Ang II in lung inflammation and fibrosis was clarified after the manipulation of the $A C E 2$ gene in transgenic mice. Mice with deletion of the ACE2 gene experienced enhanced vascular permeability, increased lung edema, and neutrophil accumulation in SARS-CoV lung infection [41, 42]. Accordingly, Sodhi et al. [42] detected increased IL-17 and neutrophil infiltration amplified by STAR3 pathway in a mouse model of Pseudomonas aeruginosa lung infection. This effect was suppressed by administration of angiotensin receptor blockers (ARB) [42]. Ang II is also associated with excessive deposition of extracellular matrix, resulting in pulmonary fibrosis [43]. This event is particularly harmful, as it results in thickened alveolar walls, reduced lung compliance, and decreased oxygen diffusion. 
The activity of Ang II in the central nervous system (CNS) has been associated with control of vascular and body fluid homeostasis, stimulation of vasopressin release, thirst, salt intake, and enhancement of the sympathoadrenal system [44]. The RAAS in the brain is influenced by both endogenous and peripheral circulation of its molecules, as AT1R has been found in circumventricular organs, cerebrovascular endothelial cells and neurons [45]. Other recently described functions of Ang II in the CNS include the response to stress, stroke susceptibility, and development of certain neuropsychiatric diseases [45]. The concentration of AT1 receptors in the hypothalamic areas belonging to the hypothalamic-pituitary-adrenal (HPA) axis, including the area responsible for corticotrophin-releasing hormone (CRH) synthesis, is associated with Ang II signaling in response to stress [45]. The AT1R is also abundant in the pituitary and adrenal glands, corroborating this hypothesis [44]. Indeed, peripheral sympathetic nerve stimulation led to increased renin activity and therefore increased levels of Ang II [44]. Thus, prophylactic AT1R blockade outside and inside the blood-brain barrier in mice has been shown to reduce activation of the HPA axis and increase catecholamine synthesis [44]. Selective inhibition of AT1R in spontaneously hypertensive rats with middle brain artery occlusion significantly reduced ischemia and tissue swelling, besides diminishing BP due to Ang II-mediated NO release. Moreover, the expression of AT1R in the limbic system also suggests a key role of the classical RAAS axis as a neuroendocrine modulator in neuropsychiatric disorders. Agtdeficient mice presented less depressive-like behavior than wild-type animals [44]. ARB administration has also been reported to exert anti-depressant-like effects in mice subjected to the forced swim test [44].

The RAAS also has important influences on metabolism. For example, in vitro studies have demonstrated that Ang II stimulates lipogenesis in human adipocytes [35]. Mice overexpressing Agt in adipose tissue exhibited systemic insulin resistance and inflammation [46]. Similarly, Agt gene deletion reduced weight gain of animals under a high-fat diet compared with wild-type mice [47]. Ang II-AT1R binding negatively regulates insulin-induced phosphorylation of the insulinreceptor (IR) [48]. In addition, Ang II directly interferes in AMPK signaling, causing insulin resistance and inhibiting adiponectin secretion [48].

In the liver, Ang II is able to enhance hepatic fibrosis due to upregulation of TGF- $\beta 1$ and activation of Kupffer cells [49]. Accordingly, the ARB candesartan and the ACE inhibitor (ACEI) perindopril significantly decreased hepatic fibrosis in animal models [49]. Furthermore, several studies proved the major role of RAAS axes imbalance in cirrhotic patients and rats with liver fibrosis [50-52]. In the hepatorenal syndrome, Ang II also seems to promote kidney vasoconstriction secondary to chronic liver disease and advanced hepatic failure [49].
Several of the previously mentioned ACE/Ang II/AT1R physiological effects rely on immune system activation. The pro-inflammatory effects of Ang II-AT1R binding have specific signaling pathways for each cell line, immune and nonimmune mechanisms. Ang II-mediated macrophage activation, for example, increases TNF, IL-1beta, IL-6, and IL-10, as well as ROS production [35]. Lymphocytes, which express RAAS components such as the AT1R, are crucial for the Ang II-induced vascular inflammation, ROS production, and hypertension [35]. T lymphocytes activated by Ang II increase $\mathrm{CC}$ chemokine receptors (CCR), whose binding increases lymphocyte and leucocyte recruitment and is associated with thrombotic events. Neutrophils are also increased by Ang II stimulation and play a key role in Ang II-induced cardiac and pulmonary fibrosis $[38,43]$.

\section{The alternative RAAS axis}

The alternative RAAS axis, with its main biologically active product Ang (1-7) has only been well characterized relatively recently. Since the initial description of Ang (1-7) binding to the Mas receptor, our understanding of the alternative or counterregulatory RAAS axis has grown [11]. Ang-(1-7) can be produced by two different pathways: in the extracellular compartment, as blood and interstitial fluid of several organs, or in the intracellular environment, as inside the mitochondria. The most common pathway is the conversion of Ang II into Ang-(1-7) by means of ACE2 (Fig. 1). Ang-(1-7) may also be synthesized by other endopeptidases, including prolyl-endopeptidase (PEP) and neprilysin (NEP), forming Ang-(1-7) directly from Ang I [1].

ACE2, a monocarboxypeptidase responsible for converting Ang II into Ang-(1-7), is an ACE homologue (42\% homology) and formed of 805 amino acids $(\sim 120$ $\mathrm{kDa})$. As with ACE, the ACE2 protein sequence reveals a hydrophobic site near the $\mathrm{C}$-terminus and a potential signal peptide at the N-terminus, which together classify ACE2 as a type-I integral membrane protein containing the zinc metallopeptidase catalytic site [10]. Thus, when the membrane-bound ectodomain of ACE2 is cleaved by the metalloproteinase ADAM17, ACE2 is released in the circulation [53]. The specificity of ACE2 is not limited to Ang II or RAAS peptides, as this enzyme has a multifunctional nature and may also exert effects on many other vasoactive peptides, including apelin-36, apelin-13, kinin metabolites kallidin, neurotensin, kinetensin, and opioid peptides [53]. Other enzymes, such as NEP, PEP, and prolyl-carboxy-peptidase (PCP), have been described as biochemically capable of producing Ang-(1-7) from Ang II and Ang I [54]. NEP is a membrane-anchored metalloendopeptidase [55]. Despite its initial description as an opiate pentapeptide encephalin hydrolyzer, NEP is capable of forming (1) Ang-(1-4) from Ang II, (2) Ang I from Ang-(1-12), and (3) Ang-(1-7) from 
Ang I [55]. This last conversion is due to the hydrolysis of the Pro7-Phe8 from Ang I, generating Ang-(1-7). NEP is expressed in several peripheral tissues [55] and its actions on the kidney appear to be of critical importance [54]. PEP, in turn, is a soluble intracellular serine peptidase that cleaves Ang I and Ang II to form Ang-(1-7). Nonetheless, this enzyme has already been found in transmembrane and nuclear forms [56], although its actions are still unclear. Lastly, PCP is a monocarboxypeptidase, with specificity for the C-terminal hydrolysis of the Pro- $\mathrm{X}$ bond, where $\mathrm{X}$ is a hydrophobic residue and is also responsible for converting Ang II into Ang-(17) [55].

Ang-(1-7) is a heptapeptide (Asp-Arg-Val-Tyr-Ile-HisPro) formed from Ang I or Ang II, as previously mentioned. The most important difference between Ang II and Ang-(1-7) is a phenylalanine amino acid on the N-terminal of the first molecule. This phenylalanine is crucial to Ang II binding to AT1R, explaining the lower affinity of Ang-(1-7) to AT1R and higher affinity to the Mas receptor [6]. The signaling mechanism of Ang-(1-7) is still poorly understood, but it has been postulated to activate the phosphatidylinolsiol-3-kinaseAkt pathway and/or the MAPKs (mitogen-activated protein kinase), and/or the c-AMP-dependent protein kinase (PKA) in different tissues [57]. Pharmacokinetic experiments determined that, in humans, Ang-(1-7) half-life is $\sim 0.5 \mathrm{~h}$ [53], normally being hydrolyzed by aminopeptidases, forming Ang-(2-7) and Ang-(3-7), or by ACE, forming Ang-(1-5) [1]. Despite being able to bind to the AT2R, the main effects of Ang-(1-7) are related to its binding to the Mas receptor.

The Mas receptor was first described in 1986 as a protooncogene due to its capability to induce cell transformation via small GTPase p21-Rac2 [58]. Afterwards, computational analysis of the amino acid sequence of the Mas receptor revealed that it is indeed a $G$ protein-coupled receptor with seven transmembrane domains. The Mas receptor gene, $M A S 1$, is located in close proximity to the imprinted $I g f 2 r$ gene in the human genome, being biallelically expressed [59]. The MasR is mainly expressed in the brain, testicles, kidneys, and heart [53]. Its signaling pathways require better understanding. However, the proposed mechanisms include the inhibition of ROS production, as well as MAP Kinases, and the activation of phosphatases, phosphorylation of Akt/ eNOS, and counter-regulation of Ang II actions [57].

The primary effects elicited by the binding of Ang-(1-7) to Mas receptor include (1) decreased aldosterone production, (2) stimulation of anti-diuretic hormone release [7], (3) inhibition of sympathetic tone, (4) reduction of BP, (5) vasodilation [1], (6) decrease of cardiac hypertrophy, (7) anti-fibrosis, (8) anti-inflammatory actions [12], (9) inhibition of VSMC growth, (10) suppression of ROS production, and (11) promotion of tissue protection [1]. Moreover, Ang-(1-7) also enhances insulin sensitivity, increases glycogen synthesis, and stimulates lipid metabolism [60].
Experimental studies have pointed to an important NEPmediated production of Ang-(1-7) in the kidney [54]. However, human production of Ang-(1-7) is mainly attributed to ACE2 [1]. The activation of ACE2/Ang-(1-7)/Mas receptor axis exerts protective roles by reducing oxidative stress, inflammation, cell proliferation, and fibrosis [12]. Several studies have shown that the renal actions of Ang-(1-7) may vary depending on the part of the nephron, type of study, or intervention applied. Sometimes Ang-(1-7) acts as a natriuretic molecule, while, in other studies, it exerts anti-diuretic effects [61]. Moreover, studies support that Ang-(1-7) has an important physiological role for the regulation of glomerular filtration, water, and sodium handling [61]. By opposing Ang II effects, Ang-(1-7) reduces glomerulosclerosis and BP, attenuating plasma elevations of urea and creatinine and preserving cardiac function [61].

The cardiovascular actions of Ang-(1-7) are also important. The inhibition of the classical RAAS axis by therapy with ACEI and ARBs improves the outcomes of patients with hypertension, acute myocardial infarction, and chronic heart failure [62]. The beneficial effects of the alternative axis in cardiac tissue can be attributed to bradykinin potentiation or counterregulation of Ang II actions, leading to anti-fibrotic, anti-inflammatory, and anti-proliferative responses [63]. In the heart, Ang-(1-7) can modulate heart rate, maintain calcium homeostasis, and promote coronary vasodilation, mostly due to prostacyclin and NO release [63]. In blood vessels, Ang-(1-7) causes vasodilation, increases NO and prostaglandin release, reduces thrombus size, and raises stem/progenitor cell proliferation and migration to vascular repair, among other actions [63].

In the respiratory system, the alternative RAAS axis has been identified as crucial for the reduction of inflammatory, fibrogenic, and proliferative effects of ACE/Ang II/AT1 axis in several pulmonary disorders [64]. ACE2 administration reduces oxidative stress and inflammatory mediators in lung tissue [64]. Moreover, experimental and clinical evidence indicate the classical RAAS axis activation and subsequent increase of Ang II take part in the pathophysiology of allergic pulmonary diseases, including asthma [65]. Regarding pulmonary fibrosis, Ang-(1-7) acts as an anti-fibrotic pulmonary survival factor by many mechanisms: cardiac protection, lung ischemia prevention, inhibition of ROS generation, and opposition to Ang II inflammatory and fibrogenic effects [65].

Ang-(1-7) has been described as playing an important role in the brain as a neuromodulator, mostly in areas related to tonic and reflex control of arterial pressure. Guimarães et al. [66] demonstrated that Ang-(1-7) is able to diminish BP in DOCA-salt hypertensive rats due to enhancement of the baroreflex bradycardia, restoration of baroreflex control of renal sympathetic activity, and regaining the balance of cardiac autonomic tone. These findings are reinforced by the improvement of baroreflex control of heart rate in 
normotensive and in hypertensive animal models [67]. Other studies suggest that the activation of ACE2/Ang-(17)/Mas axis in the brain might play an important protective role against cardiovascular and metabolic disorders [68]. Mecca et al. [69] have shown the association between central administration of Ang-(1-7) and reduction in brain damage, as well as improved neurological outcomes in animals with ischemic stroke. These beneficial effects may be due to the stimulation of angiogenesis and the antiinflammatory effects of Ang-(1-7) [67]. Moreover, it has also been proposed that Ang-(1-7) possesses neuromodulator actions by influencing the release of certain neurotransmitters (Kow and Pfaff 1988), including norepinephrine, GABA, substance $\mathrm{P}$, glutamate, taurine, and dopamine [67].

Recent studies have suggested that the alternative RAAS axis exerts several metabolic actions, including modulation of hormone secretion in pancreas, adipose tissue, liver, and reproductive organs [60]. Ang-(1-7) improves whole-body insulin resistance, while its direct action on the glucagon pathway is still unclear [60]. In adipose tissue, high levels of Ang-(1-7) are associated with increased adiponectin and reduced leptin levels. In addition, researchers aim to clarify the actions of RAAS and complications of metabolic disorders associated with increased body adiposity, like diabetes mellitus (DM) [60]. In the reproductive system, ACE2/Ang-(1-7)/ Mas axis molecules were found in ovarian follicles and testicle cells [60]. Although the exact effects on those organs are still unclear, evidence suggests the participation of the RAAS alternative axis in the regulation of gonadotropic hormones [60].

Ang-(1-7)-MasR binding has also been related to restoration of liver function, as shown in experimental studies [49]. Santos et al. [70] showed the association between MasR genetic deletion in FVB/N mice and dyslipidemia, increased abdominal fat, enhanced muscle triglycerides, glucose intolerance, and reduced insulin sensitivity. In addition, studies with ARBs, such as captopril and losartan, showed the role of these drugs in preventing tissue fibrosis and restoring liver function both in experimental and clinical studies [49]. Preclinical studies also pointed to ACE2 activity as an important endogenous negative regulator of chronic liver injury [51]. These results are reinforced by the downregulation of key genes involved in liver fibrosis after Ang-(1-7) infusion and the aggravation of liver fibrosis after pharmacological blockage of the Mas receptor [51, 52]. More recently, studies suggest that low levels of ACE2 may be a useful indicator of poor prognosis in patients with cirrhosis [49].

In terms of immune response, the ACE2/Ang-(1-7)/MasR axis inhibits the biological pro-inflammatory effects of Ang II, causing anti-inflammatory, anti-proliferative, and anti-fibrotic responses $[1,4,12]$. In inflammatory diseases, including arthritis, acute lung injury, asthma, and diabetic nephropathy, several studies have concluded that (1) Ang-(1-7) reduced leukocyte recruitment and the production and expression of chemokines, cytokines, and adhesion molecules and (2) the Mas receptor increased neutrophil apoptosis and stimulated the alternative macrophage activation [12]. In addition, studies using the Mas receptor agonist AVE0991 demonstrated reduced accumulation of neutrophils and pro-inflammatory cytokines [12].

Table 1 summarizes the main effects of the two RAAS axes in different organs, systems, and disease conditions, including several not directly discussed here.

\section{Other RAAS peptides}

Discovery of several novel molecules and pathways of the RAAS cascade has led to the present view of the RAAS as comprising two main axes (Fig. 2). Indeed, components of the RAAS, including angiotensin-(1-9) (Ang-(1-9)) and alamandine, for instance, show relevant biological effects, but the physiological role of these molecules in the context of the counter-regulation of the classical RAAS axis remains unclear, especially in humans. It should be mentioned that the endogenous and physiological relevance of a molecule encompasses the existence of an enzyme that synthesizes the molecule and a specific receptor that mediates the biological effects of it. Therefore, the activity of an axis depends mostly on (1) the peptide's concentration, (2) the enzyme-substrate affinity, (3) the peptide-receptor affinity, and (4) the expression of its receptor. Despite the existence of angiotensin peptides that have their own receptors such as alamandine and the Mas-related G protein-coupled receptor member $\mathrm{D}(\mathrm{MrgD})$, for example, the physiological role of this molecule has not been clearly established. Alamandine concentration is physiologically low, as reported in several experimental studies [71]. Further investigation is needed for better understanding of the functions and pharmacological potential of these novel RAAS fragments as an escape route for both classical and alternative arms.

Alamandine is mainly produced following the hydrolysis of Ang-(1-7), in which the aspartate radical group in the amino terminal sequence is cleaved by aspartate decarboxylase [72, 73]. Other possible pathways to form alamandine are from angiotensin A (Ang A), following the enzymatic action of ACE2 [1]. Alamandine binds to the MrgD, a receptor previously reported in relation to neuropathic pain and the perception of itching [74]. Alamandine-MrgD interaction has been shown to exert cardiovascular effects, as studies observed vasodilation after the administration of alamandine in spontaneously hypertensive rats [74]. Alamandine also increases eNOS expression and promotes both central and local NO-mediated vasodilation, capable of reversing endothelial dysfunction [74]. De Jesus et al. [75] also demonstrated the anti-hypertrophic counter-regulatory role of the ACE2/alamandine/MrgD axis in Ang II hypertrophy rat cardiomyocytes due to activation of 
Table 1 Effects of the classical and alternative RAS axes in human organs, systems, and disease conditions

\begin{tabular}{|c|c|c|}
\hline & ACE/AngII/AT1R & ACE2/Ang-(1-7)/MasR \\
\hline Kidney & $\begin{array}{l}\text { - Decrease renal blood flow } \\
\text { - Increase of glomerular hypertension by efferent arteriole } \\
\text { vasoconstriction } \\
\text { - Enhance glomerular damage } \\
\text { - Stimulation of sympathetic nervous system } \\
\text { - Increase of aldosterone secretion } \\
\text { - Increase of renal inflammation and fibrosis }\end{array}$ & $\begin{array}{l}\text { - Increase of renal blood flow } \\
\text { - Reduction of glomerular hypertension } \\
\text { - Decrease of proteinuria } \\
\text { - Control of sodium and water handling } \\
\text { - Decrease of aldosterone secretion } \\
\text { - Inhibition of sympathetic tone } \\
\text { - Reduction of oxidative stress, inflammation, cell proliferation, } \\
\text { and fibrosis }\end{array}$ \\
\hline Heart & $\begin{array}{l}\text { - Stimulation of fibrotic, inflammatory, and proliferative } \\
\text { responses } \\
\text { - Increase of arrhythmias } \\
\text { - Enhance of endothelial dysfunction } \\
\text { - Stimulation of cardiac remodeling and hypertrophy }\end{array}$ & $\begin{array}{l}\text { - Anti-fibrotic, anti-inflammatory, and anti-proliferative effects } \\
\text { - Modulation of inotropic response } \\
\text { - Stimulation of coronary vasodilation }\end{array}$ \\
\hline Lung & $\begin{array}{l}\text { - Stimulation of fibrotic, inflammatory, and proliferative } \\
\text { responses } \\
\text { - Stimulation of pulmonary vascular remodeling } \\
\text { - Decrease oxygen diffusion and reduce lung compliance }\end{array}$ & $\begin{array}{l}\text { - Anti-fibrotic, anti-inflammatory, and anti-proliferative effects } \\
\text { - Reduction of oxidative stress } \\
\text { - Prevention of lung ischemia }\end{array}$ \\
\hline Brain & $\begin{array}{l}\text { - Modulation of vascular and body fluid homeostasis } \\
\text { - Modulation of stress response } \\
\text { - Modulation of neuroendocrine changes }\end{array}$ & $\begin{array}{l}\text { - Improvement of baroreflex gain } \\
\text { - Enhance brain oxygenation } \\
\text { - Modulation of neurotransmitter release }\end{array}$ \\
\hline $\begin{array}{c}\text { Endocrine } \\
\text { system }\end{array}$ & $\begin{array}{l}\text { - Increase of insulin resistance } \\
\text { - Increase of inflammation on adipose tissue } \\
\text { - Stimulation of lipogenesis } \\
\text { - Inhibition of adiponectin secretion }\end{array}$ & $\begin{array}{l}\text { - Improvement of insulin resistance } \\
\text { - Increase of adiponectin levels } \\
\text { - Decrease of leptin serum levels } \\
\text { - Modulation of gonadotropic hormones }\end{array}$ \\
\hline Liver & $\begin{array}{l}\text { - Increase of inflammation and fibrosis } \\
\text { - Increase of oxidative stress }\end{array}$ & $\begin{array}{l}\text { - Prevention of fibrosis and inflammation } \\
\text { - Reduction of oxidative stress }\end{array}$ \\
\hline
\end{tabular}

the AMPK/NO pathway. Furthermore, in vitro studies have demonstrated the anti-fibrotic effects of alamandine administration in isoproterenol-treated rats [72]. Although patients with CKD seem to have higher plasma levels of alamandine, the pathophysiological implications of this finding require further investigation [74].

Angiotensin III (Ang III), formed by the action of aminopeptidase A on Ang II, is capable of binding to both AT1R and AT2R [76-78]. Some research groups have postulated that Ang III is, in fact, the biological ligand to the AT2R, after the cleavage of the N-terminal aspartate residue of Ang I [76]. Along those lines, Padia et al. [79] observed increased natriuresis after Ang III infusion in rats under ARB treatment. Although effects on decreasing arterial pressure through natriuresis have been reported, other studies have demonstrated an important role of Ang III in the release of atrial natriuretic peptide and vasopressin [76]. This finding may be due to the higher expression of AT1R in comparison to AT2R in adults, as Ang III possesses greater AT2R-AT1R selectivity than Ang II [76]. Indeed, more evidence is needed to define the physiological and pharmacological properties of Ang III in vivo.

Angiotensin IV (Ang IV) is an interesting RAAS peptide with a variety of described physiological properties in the CNS. This fragment is formed following the cleavage of the arginine from the N-terminus of Ang III by aminopeptidases
$\mathrm{N}$ and B [80]. Ang IV has relevant affinity for both AT1R and AT2R, with its affinity to AT2R being superior to that of Ang-(1-7) for the same receptor [76]. In addition, Ang IV has its own receptor, the angiotensin IV G protein-coupled receptor (AT4R) [80]. Lochard et al. [81] concluded that Ang IV is only able to bind to AT1R in the presence of Ang II. The study was conducted with transgenic mice chronically releasing Ang IV in the brain, which experienced an increase in BP due to the mobilization of calcium by Ang IV via AT1R [81]. This finding supports an allosteric mechanism between AT1R and AT4R, since the administration of the AT1R antagonist candesartan reversed Ang IV effect [81]. Ang IVAT2R binding was reported to prevent endothelial dysfunction in aortic vessels due to the reduction of NO bioavailability in the development of atherosclerotic lesions [82]. The most promising properties regarding Ang IV, however, are related to its binding to AT4R, whose expression in the CNS is increased in the neocortex, hippocampus, and cerebellum [81]. Albiston et al. [83] concluded in 2001 that AT4R is actually the insulin-regulated aminopeptidase (IRAP), which substrate in vivo lacks identification. Since Ang IV has been reported to increase learning and memory recall, one current hypothesis proposes that binding of this peptide to IRAP increases the endogenous peptide's half-life by inhibiting its degradation [81]. Moreover, knowledge about the association between 
IRAP and the glucose transporter type 4 (GLUT4) suggests that Ang IV might play a distinct role in this protein translocation [81].

Angiotensin-(1-9) is directly formed by ACE2 activity on Ang I and is able to produce Ang-(1-7) after being hydrolyzed by either ACE or NEP $[1,84]$. This peptide was primarily thought to be inactive, exerting counter-regulation to the ACE/Ang II/AT1R axis by diminishing the conversion of Ang I into Ang II and consequently producing Ang-(1-7) by NEP activity [76]. However, new evidence points to physiological implications due to Ang-(1-9) binding to the AT2R receptor. Ocaranza et al. [85] were the first to identify its biological effects in the cardiovascular system, leading to anti-hypertrophic effects in neonatal and adult heart. The molecular mechanisms of Ang-(1-9) were clarified by Sotomayor-Flores et al. [86]. Considering the main role of mitochondrial dynamics and $\mathrm{Ca}^{2+}$ handling in cardiac hypertrophy, Ang-(1-9) administration increased mitochondrial fusion and reduced mitochondrial fission and intracellular calcium dysregulation, therefore exerting anti-hypertrophic effects [86]. Previous studies also associated Ang-(1-7) and modulation of pro-fibrotic pathways, decreasing cardiac fibrosis [85]. Moreover, Cha et al. [87] observed beneficial results after the administration of Ang-(1-9) in pulmonary hypertensive rat models, by altering the expression of apoptosis-related proteins via AT2R. Although Ang-(1-9) affinity to the AT2R receptor is only moderate ( 100 -fold lower than Ang II), this peptide has also been described to enhance bradykinin action and arachidonic acid release [76].

Angiotensin-(1-12) (Ang-(1-12)) plays an intriguing role in understanding the noncanonical pathways of the RAAS [88]. Ang-(1-12) can be cleaved by NEP and ACE to form Ang I, at least in the kidney [55]. Although Ang-(1-12) can be formed from angiotensin-(1-14), Ahmad et al. [89] proposed that Ang-(1-12) might be produced after cleavage of Agt by a member of the kallikrein enzyme system. Well-established data have demonstrated renin-independent cardiac Ang II formation and function throughout the years, mainly by the chymase-mediated hydrolysis of Ang-(1-12) and Ang I in rat models and normal human left ventricles. In this matter, the translational research comparing rodents and human cardiac tissue reveals that the chymase rather than renin might be the primary pathway to form Ang II, which may explain the limited results regarding ACEI and ARB treatment for preventing Ang II production in cardiovascular disease [89]. Further investigation on Ang-(1-12) might unravel a novel perspective on pharmacology related to the RAAS.

Lastly, angiotensin A (Ang A) was identified by Jankowski et al. in 2007 [90]. This octapeptide is very similar to Ang II's amino acid sequence, differing only by an alanine (Ala-ArgVal-Tyr-Ile-His-Pro-Phe) instead of an aspartate [80]. Although some affinity to the AT2R receptor has been described, this molecule is considered to have intrinsic vasoconstrictive and pro-hypertensive effects via the AT1R, with similar binding affinity as Ang II [91]. Physiological plasma concentration of Ang A is about $20 \%$ of the concentration of Ang II, and its potency of vasoconstriction is one tenth that of Ang II [91]. However, similarly to alamandine, patients with stage 5 CKD showed higher Ang A/II ratio than healthy controls [91]. This finding corroborates the supposed escape route of other RAAS fragments in compromising diseases of the kidney parenchyma. Again, the existence of alternative peptides could help understanding the partial results of classical RAAS blocker therapy in treating cardiovascular and kidney diseases. In this context, an interesting perspective might be the evaluation of the angiotensin A effects via AT2R after the administration of ARBs.

\section{Role of classical and alternative RAAS axes in pediatric kidney diseases}

\section{Pediatric hypertension}

The role of the kidney in hypertension is mainly based on sodium and water retention, changes in pressure natriuresis, impaired kidney autoregulation, and systemic and local activation of the classical RAAS axis [4]. However, literature regarding HTN and the RAAS are controversial. Some research groups have found higher Ang-(1-7) levels in hypertensive adults, while other studies have reported normal levels [61]. In the only study to include children, we found that levels of Ang II in patients with renovascular hypertension were higher than levels of Ang-(1-7) [92]. In addition, after intervention and correction of renal artery stenosis, levels of RAAS molecules were restored to normal. In contrast, the study showed that patients with primary HTN had significant elevation of circulating levels of Ang-(1-7), while the levels of Ang I and Ang II were within the normal range [92]. Ang-(1-7), in this sense, might play a key role as a biological marker of primary HTN, as the elevation of Ang-(1-7) plasma levels may be conceived as a compensatory mechanism to oppose the deleterious effects of ACE/Ang II/AT1R upregulation.

The childhood obesity epidemic has highlighted the importance of excess weight as a risk factor for HTN development [93]. A cross-sectional analysis conducted by South et al. [94] investigated the association between very low birth weight in preterm newborns, plasma and urinary Ang II and Ang-(1-7), and body weight. Results from 175 participants showed that obesity was associated with high BP, increased Ang II, and reduced Ang-(1-7) both in circulation and in the kidney [94]. Therefore, obesity may increase the risk of HTN and cardiovascular diseases in individuals born prematurely by further augmenting the prematurity-associated imbalance of the RAAS. 
Another intriguing issue related to renal arterial hypertension is the potential protective role of a low-sodium/high-potassium diet $[95,96]$. High-salt intake is clearly associated with an elevation of BP, a greater risk of albuminuria and of adverse kidney and cardiovascular outcomes compared with low or moderate sodium intake. On the other hand, a potassium-rich diet has been associated with a lower incidence of HTN, stroke, nephrolithiasis, and kidney disease [95, 96]. Several mechanisms may be involved in the responses to lowsodium and high-potassium intake, including decreased sensitivity of VSMCs to Ang II and catecholamines, modulation of baroceptor sensitivity, reduction of sympathetic activity, increased urinary sodium excretion, decreased renal vascular resistance, and increased GFR $[95,96]$.

In a recent study of fetal programming, ACE2/Ang-(1-7)/ Mas receptor axis and cardiovascular events were associated with persistent alterations in Ang-(1-7) in the circulation and kidney during adolescence and abnormal kidney sodium handling, HTN, and cardiovascular disease in adulthood [97]. Therefore, both RAAS axes not only exert a critical physiological role on BP homeostasis but also take part in the pathophysiology of arterial HTN in pediatric patients.

\section{Glomerular diseases}

The RAAS exerts a central role in the pathophysiology of glomerular disease, especially in the progression to CKD, as previously shown in several studies. Therefore, treatment with RAAS blockers has been shown to reduce proteinuria and exert renoprotective effects in almost all glomerular diseases [61]. Pinheiro et al. [98] reported significant changes in kidney function and histology secondary to the genetic deletion of Mas receptor gene in mice, including (1) reduced renal blood flow; (2) glomerular hypertension with consequent increased urinary albumin excretion; (3) reduction in the diameters of the glomerular tuft and Bowman's capsule; (4) increased deposition of collagen III, collagen IV, and fibronectin; and (5) increase of AT1R and TGF- $\beta$ RNA expression in kidney tissue. These results corroborate previous studies by showing that Ang-(1-7) may act as a physiological regulator of intraglomerular pressure and may oppose Ang II's proinflammatory and pro-fibrotic effects [1]. Additionally, Silveira et al. [99] demonstrated beneficial effects of Mas receptor activation in a murine model of adriamycin-induced nephropathy. Treatment with AVE0991, an agonist of the Mas receptor, improved kidney function parameters, reduced urinary protein loss, attenuated histological changes on kidney tissue, and decreased urinary levels of fibrogenic cytokines such as TGF- $\beta 1$ [99]. The study also showed that mRNA expression of AT1R and Mas receptors were both decreased in adriamycin-induced nephropathy. More importantly, the renoprotective effects of losartan in this experimental model were dependent on Mas receptor activation [99].
A recent study by Silva-Filha et al. [100] analyzed the role of both RAAS axes in pediatric patients with primary nephrotic syndrome (NS). Thirty-one patients with primary NS and 19 healthy controls underwent urine collection for measurement of RAAS molecules [99]. The analysis showed that primary NS patients had reduced urinary levels of ACE2, but increased urinary concentrations of Ang II, Ang-(1-7), and ACE [100]. Additionally, reduced ACE2 levels were negatively correlated with proteinuria in patients with primary NS [100]. Previous studies had already indicated that acquired or genetic deficiency of ACE2 increased kidney injury and proteinuria in other kidney diseases [61], probably due to potentiation of Ang II effects. Furthermore, Nadarajah et al. [101] showed that the overexpression of ACE2 in glomerular podocytes attenuated the development of diabetic nephropathy in mice, apparently as a result of delaying the development of albuminuria. This study also demonstrated that ACE2 overexpression attenuates histological changes, preserves podocyte proteins, avoids podocyte loss, and reduces TGF- $\beta 1$ expression [101]. Taken together, these findings support a renoprotective role of ACE2 in glomerular diseases.

The apparently counterintuitive finding of high urine concentrations of Ang-(1-7) in parallel with lower urinary levels of ACE2 in pediatric patients with primary NS, might be explained by the compensatory response to kidney damage triggered by high-level activation of the classical RAAS axis [100]. Other explanations include the synthesis of Ang-(1-7) by other enzymes, such as NEP and PEP, and the diminished MasR expression in kidney tissue, as reported by $\mathrm{Ng}$ et al. [102]. Another important aspect in regard to glomerular diseases and the role of both RAAS axes are the interactions between components of the RAAS and inflammatory mediators in the context of glomerular diseases. Therefore, current evidence strongly supports the important role of inflammation for kidney injury in glomerular diseases. Pediatric patients with primary NS had significantly higher concentrations of MCP-1/CCL2, a pro-inflammatory chemokine related to macrophage activation than controls without NS [100]. In addition, urine concentrations of IP-10/CXCLS-10, a cytokine responsible for chemotactic effects, apoptosis, and cell growth, were positively correlated to proteinuria [100]. Moreover, urinary levels of Ang-(1-7) and ACE2 were negatively correlated with MCP-1/CCL2 and IP-10/CSCL-10, respectively, suggesting that both RAAS molecules interact with inflammatory pathways in glomerular diseases.

Well-established data associate low birth weight with systemic diseases in childhood and adult life, including HTN, insulin resistance, and coronary heart disease [103]. Previous studies with animal models demonstrated that intrauterine growth restriction (IUGR) impairs kidney development and leads to a reduced number of nephrons, with consequent development of glomerular hyperfiltration after birth and ultimately, kidney damage in adulthood [103]. Analysis of serum 
levels of RAAS components in a rat model of nephrotic syndrome induced by prenatal ethanol exposure demonstrated (1) increased serum levels of Ang II, probably due to higher proportion of ACE in relation to ACE2; (2) reduced AT2R expression; and (3) reduced ACE2 and Mas receptor expression. Additionally, prenatal ethanol exposure was shown to inhibit normal kidney development, probably due to overexpression of Cdh11 and consequent growth retardation of ureteric bud (UB) branching. Finally, intrauterine programming might be impaired by ethanol damage at critical stages of development. In other words, epigenetic modifications might also be responsible for modulating the expression of RAAS molecules, resulting in, for instance, low expression of renal AT2R [104].

\section{Congenital anomalies of the kidney and urinary tract}

The classical RAAS axis seems to have an important role in CAKUT. High levels of Ang II lead to reduced renal blood flow, causing ischemia and kidney growth arrest of the impaired kidney. Although renal blood flow usually normalizes 6 weeks after the relief of temporary obstruction, kidney growth remains altered, suggesting that other factors are responsible for growth impairment, including the reduction of cell proliferation, increased cell apoptosis, and progression of interstitial fibrosis [105]. Ang II also increases the expression of TNF- $\alpha$ mRNA in obstructed kidneys, enhancing the interest in ACEI drugs as an effective prevention of kidney fibrosis in CAKUT [105].

Specifically, in ureteropelvic junction obstruction (UPJO), the AGTR2 gene, responsible for AT2 receptor expression, appears to have two main actions in relation to urethral development: (1) the regulation of the apoptotic process in undifferentiated mesenchymal cells surrounding the developing ureter and (2) inhibition of ectopic ureteral budding [105]. Additionally, increased urinary levels of ACE2 and of Ang-(1-7) as well as lower ACE urinary levels were detected in fetuses with posterior urethral valves (PUV) when compared with healthy neonates [106]. The explanation for the increased levels of molecules of the alternative RAAS axis relies on the potential role of ACE2 and Ang-(1-7) as a compensatory mechanism against the intense inflammatory response process triggered by PUV itself [106].

\section{Chronic kidney disease}

Chronic kidney disease in pediatrics mostly results from CAKUT and glomerular and cystic diseases and evolves with HTN. Results from The Chronic Kidney Disease in Children Study Group showed that 37\% of CKD pediatric patients had systolic or diastolic BP measurements above the 90th percentile for correspondent age and sex and 14\% met the diagnostic criteria for HTN [107]. The loss of glomerular autoregulation in HTN leads to development of intraglomerular hypertension, which may contribute to proteinuria and glomerular tissue damage [108]. In this setting, high BP is the consequence of disease progression and a risk factor for stage 5 CKD.

Enhanced classical RAAS axis activation results in increased Ang II production and higher stimulation of AT1 receptors, which may contribute to systemic and glomerular capillary HTN, provoking kidney injury and progression of CKD [1]. Ang-(1-7), on the other hand, induces dilatation of pre-constricted renal afferent arterioles and increases kidney blood flow, neutralizing Ang II effects [62]. Several mechanisms may explain how Ang-(1-7) counteracts kidney effects of Ang II, including (1) competition for the binding of Ang II to AT1 receptors; (2) deregulation of Ang II/AT1 signaling transduction; (3) interference of AT1 receptor syntheses; and (4) stimulation of NO release, mobilization of anti-apoptotic pathways, and reduction of oxidative stress by the activation of mitochondrial RAAS alternative axis [61]. As previously mentioned, we have found high levels of both Ang II and Ang-(1-7) in children with renovascular HTN, whereas patients with primary HTN had a selective elevation of plasma Ang-(1-7) [92]. These findings suggest upregulation of the classical RAAS axis in renovascular HTN that differ from the response of primary hypertensive pediatric patients [92]. Later studies have demonstrated that plasma levels of Ang-(17) were even more pronounced in pediatric patients with stage $5 \mathrm{CKD}$, pointing to a deviation of RAAS metabolism toward Ang-(1-7) synthesis at more advanced stages of the disease [109]. In addition, this finding might also be due to an impairment and/or downregulation of Mas receptor in patients with stage 5 CKD [109].

The pro-inflammatory and pro-fibrotic effects of Ang II may also contribute to CKD progression [12]. Ang II increases the population of inflammatory monocytes by (1) facilitating differentiation of hematopoietic stem cells; (2) stimulating adhesion molecules; (3) enhancing leukocyte rolling flux, adhesion and migration; (4) upregulating plasma levels of IL-6, IFN- $\gamma$, TNF- $\alpha$ and IL-1 $\beta$; and (5) activating calcium mobilization, among other actions [12]. Moreover, Ang II contributes to fibrogenesis and organ remodeling, while Ang-(1-7) has anti-fibrogenic and anti-proliferative effects $[1,17]$. Hence, the Ang II pro-inflammatory environment induces tissue damage, which eventually leads to progressive loss of kidney function.

$\mathrm{Ng}$ and colleagues [102] demonstrated reduction of Mas receptor expression in rats with CKD. This group also observed an association between indoxyl sulfate (IS) administration and diminished Mas receptor kidney expression, as well as increased TGF- $\beta 1$ in cultured human proximal tubular cells [102]. Sun et al. [110] showed the effect of classical RAAS axis inhibitors like losartan in preventing IS-induced fibrosis on targeting organs. These data indicate that the proinflammatory reactions and enhancement of oxidative stress 
of this uremic toxin may be the result of classical RAAS axis activation [111]. Moreover, the inhibition of these pathways might slow the development of CKD through indirect RAAS suppression.

Consistent with these findings, Ma et al. [112] found that mice with genetic deletion of the AT2 receptor gene have (1) decreased cortical ACE2 activity, Mas expression, and Ang-(1-7) levels in kidney tissue; (2) increased production of ACE, Ang II, and AT1 receptor in kidney cortex; (3) high $\mathrm{BP}$, increased indices of kidney injury, and mesangial matrix expansion score; and (4) microalbuminuria. Ali et al. [113] showed that AT2 and Mas receptors have molecular interactions, mainly concerning NO release and diuretic responses. The main conclusion is that the downregulation of the alternative RAAS axis can extend kidney tissue damage.

Regarding acute kidney injury (AKI), increased kidney vascular resistance due to stimulation of sympathetic nervous activity was responsible for triggering renin secretion and consequently elevation of Ang II levels [114]. The exact role of the classical RAAS axis in AKI, however, is yet to be clarified. Barroso et al. [115] detected renoprotective effects of AVE0991, a Mas receptor agonist, in experimental AKI by improving kidney function, decreasing tissue damage, preventing leukocyte infiltration, and reducing cytokine release. It should also be mentioned that AKI can lead to CKD and the activation of classical RAAS axis may also play a role in this process.

\section{Systemic diseases affecting the kidney}

Several studies have demonstrated that kidney RAAS is altered in DM patients and that RAAS inhibitors can reduce the incidence of vascular complications in these patients, probably by means of the protection of skeletal muscle and pancreatic islets, enhancement of insulin sensitivity, and reduction of adipocyte size [116]. A recent study by Alves et al. [117] showed that hyperglycemia was responsible for increased urinary levels of cytokines and kidney gene expression of IL-10, suggesting a DM modulation of kidney inflammation. Moreover, previous studies indicated the benefits of ACEI and ARBs as first-line treatments for patients with DM and HTN, mostly due to their cardiac and renoprotective effects [118]. In line with these findings, Mori et al. [119] showed that Ang-(1-7) ameliorates diabetic nephropathy through decreasing kidney inflammation and fibrosis, attenuating kidney ROS production, and reducing kidney lipotoxicity.

Sickle cell anemia (SCA), the most common hemoglobinopathy worldwide, is capable of triggering sickle cell nephropathy (SNC) as a result of a poorly understood inflammatory state [120]. There is a clear association between albuminuria in children with SCN and urinary levels of cytokines and chemokines, including IL-6, TNF, and MCP-1/CCL2. These molecules might be possible biomarkers for poorer outcomes in SCN [121]. In addition, high hemoglobin F and platelet levels were also associated with increased estimated glomerular filtration rate and albuminuria, respectively [122]. As the platelets from SCD patients can secrete higher amounts of inflammatory molecules, SCA progression is closely related to the development of SCN. Although some studies on ACEI administration showed significant reduction of albuminuria in patients with SCA, none had evaluated RAAS components in these patients. In this regard, Belisário et al. [123] performed a cross-sectional study with 72 children and showed lower levels of ACE2 and Ang-(1-7) in SCA children with persistent albuminuria. These results were the first to provide evidence for a role of RAAS molecules in human SCN, suggesting that SCA patients had RAAS imbalance towards the classical axis [123].

The RAAS is also involved in the physiopathology of autoimmune diseases, including rheumatoid arthritis and lupus nephritis (LN). LN is the result of acute kidney inflammation triggered by the deposition of autoantibodies and immune complexes in the kidney [124]. Accordingly, several studies have shown that Ang II has pro-inflammatory effects in autoimmune diseases due to regulation of chemokines, cytokines, and chemotactic agents, including TGF- $\beta 1$, TNF, IL-6, osteopontin, and NF-kappa B [125]. Similar to glomerular diseases, LN can have a wide spectrum of presentations, from minimal mesangial injury to advanced glomerular sclerosis. Likewise, both diseases might be attenuated by the use of ACEI and ARBs, in order to provide renoprotection and reduction of proteinuria [124]. Albuquerque et al. [126] showed that captopril was able to reduce TGF- $\beta 1$ expression in the glomeruli and TGF- $\beta 2$ expression in the periglomerular region of mice with lupus. Furthermore, it was proposed that captopril changes the cytokine profile of LN patients through inhibition of Ang II effects on lymphoid cells and apoptosis signal complexes [126].

All of these data support the main role of classical RAAS axis activation in the pathophysiology of kidney damage triggered by systemic diseases and open the possibility of novel therapeutic approaches by stimulation of the alternative RAAS axis.

\section{RAAS and COVID-19}

The outbreak of SARS-CoV-2 virus infection in Wuhan, China, in 2019 has led to increased scrutiny of the role of the RAAS in patients with novel coronavirus disease (COVID-19). Early in the pandemic, several studies pointed to a pivotal role of transmembrane ACE2 as a viral receptor in nasal and oropharyngeal epithelia [127]. Hence, researchers postulated about the function of the RAAS in COVID-19, where a hypothesis of RAAS imbalance might explain the disease's clinical findings [40]. The intersection between 
COVID-19, RAAS, and pediatrics is particularly intriguing, due to the epidemiological pattern confirmed in several reports worldwide: lower frequency, severity, and fatality case rates in the pediatric population [128].

Although COVID-19 occurs in all age groups, the number of cases in children is overall low. In China, data from the Chinese Center for Disease Control and Prevention reported a percentage of $2.2 \%$ confirmed cases of COVID-19 among patients aged $<19$ years old [129]. In the USA, a report from the Center for Disease Control (CDC) showed that only $2 \%$ of COVID-19 cases were under 18 years old [130]. In Europe, the incidence is even lower, with $1.2 \%$ of Italian patients and $0.8 \%$ of Spanish cases being $<18$ years of age [131]. A comparison with adult patients made by Wu et al. [132] showed a milder clinical presentation of children positive for COVID19 in the following signs and symptoms: fever (36\% for pediatric cases versus $86 \%$ for adult patients), cough (19\% vs. $62 \%$ ), elevated C reactive protein ( $3 \%$ vs. $49 \%$ ), and pneumonia (53\% vs. 95\%). This finding was also confirmed by the American CDC regarding fever (56\% for pediatric cases versus $71 \%$ for adult patients), cough ( $54 \%$ vs. $80 \%)$, and dyspnea (13\% vs. $43 \%)$ [133]. Furthermore, American information on hospitalization status of 745 COVID-19 pediatric cases under the age of 18 presented a percentage of $5.7 \%$ of hospitalization and $0.58 \%$ of admission to the intensive care unit (ICU). In comparison, among the 35,061 adult cases, $20 \%$ were hospitalized and $2.0 \%$ went to ICU [133]. Mortality of children with COVID-19 has been rare, consistent with the seemingly milder course of the infection in those $<19$ years old.

The significance of these data is counterintuitive in light of the well-established higher susceptibility rates of infants to respiratory infections [134]. Therefore, the theoretical protection of children from SARS-CoV-2 infection suggests the reevaluation of COVID-19 as a systemic condition with pulmonary involvement, rather than a pulmonary disease with systemic implications [135]. The various manifestations of COVID-19 in pediatric patients might be a result of different and multifactorial defense mechanisms involving the RAAS dynamism throughout life, as well as its implications on disease course, and the naïve immune system, which is not fully developed in these patients. Pediatric symptomatology supports this hypothesis, as systemic complications have frequently been reported, including sore throat, vomiting, diarrhea, and abdominal pain [130].

Indeed, the pathophysiology of COVID-19 might rely greatly on imbalance of the RAAS. Binding of the viral spike glycoprotein $\mathrm{S}$ to membrane-bound ACE2 leads to the entrance of ACE2 into the cell and as a consequence reduces the amount of active enzyme [40]. Since the RAAS has two counter-regulatory and dynamic arms, diminished ACE2 results in (1) higher Ang II levels, as well as classical arm ACE/ Ang II/AT1R upregulation and (2) Ang-(1-7) depletion and consequent ACE2/Ang-(1-7)/MasR downregulation. The deleterious effects of Ang II in pulmonary, inflammatory conditions have been previously discussed in this article. Hence, the imbalance of both RAAS axes may be responsible for disease progress in three main phases: hematological, pulmonary, and inflammatory [40]. The first phase might be the result of SARS-CoV-2 invasion of hematopoietic stem/progenitor cells (HSPC) expressing ACE2, leading to the significantly high frequency of lymphopenia and viral induced hypoxia [136]. Secondly, the pulmonary involvement possibly related to ACE/Ang II/AT1R activation, which allegedly induces lung inflammation, endothelial dysfunction, fibrosis, and pulmonary arterial HTN, leading to development of the typical acute respiratory distress syndrome (ARDS) [12]. Moreover, severe hypoxemia might be a result of hypoxic vasoconstriction and reduced ventilation-perfusion ratio [137]. This explains the widespread need for mechanical ventilation in adults with COVID-19. The third phase is a hyper-inflammatory state named cytokine storm syndrome which plays a key role in determining disease severity. A range of immune-related cascades might be activated by the exacerbation of ACE/Ang II/AT1R, including the synthesis and release of pro-inflammatory cytokines, including IL-1, IL-6, and TNF- $\alpha$ [137]. This process, added to viral intrinsic activation of both innate and adaptive immune systems, may explain the higher levels of IL-6, IL-2R, IL-10, and TNF- $\alpha$, as well as lower CD4+ and CD8+ levels in COVID-19 patients [138]. Pediatric patients, in particular, presented increased serum creatine kinase $\mathrm{MB}$, procalcitonin and $\mathrm{C}$ reactive protein, lymphocytopenia, and leukopenia associated with higher disease severity [139]. The three presented mechanisms result in alveolar edema and vascular leakage, both responsible for hypoxia and dyspnea [139].

Due to the relevance of the RAAS imbalance hypothesis in the pathophysiological course of the disease, researchers have pursued the presumable beneficial effects of RAAS blocker therapy in COVID-19. The main purpose is to prevent the exacerbation of the ACE/Ang II/ AT1R axis, thought to be responsible for the aggravation of the condition [40]. In this sense, the National Health Institute (NIH) included several clinical trials using low doses of RAAS blocker therapy, ARBs and ACEI for instance, to evaluate the effects on preventing disease progression. Additionally, studies on Ang-(1-7) analogues and recombinant human ACE2 also seem promising. The dynamic changes of RAAS expression throughout life have been considered an important modulator of development of kidney and cardiovascular systems (Fig. 3). This physiological modulation process might be divided in three principal stages: fetal, postnatal, and puberty [140]. In fetal life, the expression of AT1 and AT2 receptors in vasculature and kidneys is greater than at any other period of 
life in response to renal and cardiovascular demands [140]. Subsequently, postnatal ontogeny implicates a decrease of AT2R expression due to kidney maturation, activation of which by Ang II plays a protective role in newborns fighting infections [141]. Similarly, higher expression of AT2R might exert a beneficial effect in COVID-19 due to its anti-inflammatory properties [28]. Research conducted by Bunyavanich et al. [142] showed an age-dependent expression of ACE2 in nasal epithelium, which was relatively low in children younger than 10 years old and progressively increased until adulthood. This may also explain the lower infectivity of COVID19 in the pediatric group. Lastly, during puberty, sexual dimorphism of arterial pressure is closely related to differential modulation of the cardiovascular system by sex hormones, which may impact upon RAAS expression. Testosterone, for instance, has been demonstrated to increase the expression of AT1 receptor and decrease the expression of AT2 in male rodents [143]. Additionally, greater ACE2 and MasR expression has been demonstrated in female rodents [144] and higher plasma Ang-(1-7) levels have been seen in women than in men [145]. These findings might explain the male predominance of COVID19 cases in both children and adults [130].

On the other hand, specific aspects of the immune system in childhood may also exert an unexpected protection in COVID-19 due to its immaturity, as disease progression and severity are correlated with a hyperimmune response. Immunity is constructed and modulated by several genetic and environmental factors from the

\section{Expression}

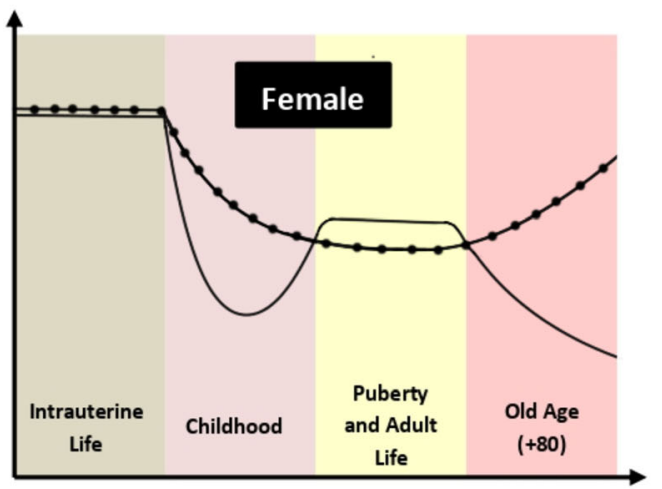

Life Stage womb until late childhood [134]. Maternal diet, vaginal health, birth period, breastfeeding, diet, hygiene, and antibiotic medication are some of the defining aspects that determine the child's capacity to fight pathogens through the improvement of the adaptive immune system. Despite depending greatly on the innate response due to the poor immunologic memory, studies on respiratory infections showed an inadequate activation or suppression of some innate components in infantsINF- $\alpha / \beta$, IL-6, and TNF- $\alpha$ for instance [134]. Furthermore, the naïve adaptive immune system has been described to present weaker $\mathrm{T}$ helper 1 (Th1) responses, limited B cell repertoire and inefficient generation of somatic hypermutations [134]. In common viral infections, these findings might contribute to greater disease severity. In COVID-19, however, the presumed disadvantage might actually be a protective mechanism, preventing cytokine storm and leading to the large number of asymptomatic and milder cases in children.

The emergence of COVID-19 represents a unique challenge for clinicians caring for patients from all age groups. Better understanding of the disease is vital so that improved clinical management and therapeutic strategies can be developed. The dynamism of the RAAS throughout life and the immature immune system in pediatric patients may be responsible for the milder clinical presentation and the epidemiological profile of COVID-19 in the young. Further investigation is necessary to completely solve the pathophysiological mechanism of the disease.

\section{Expression}

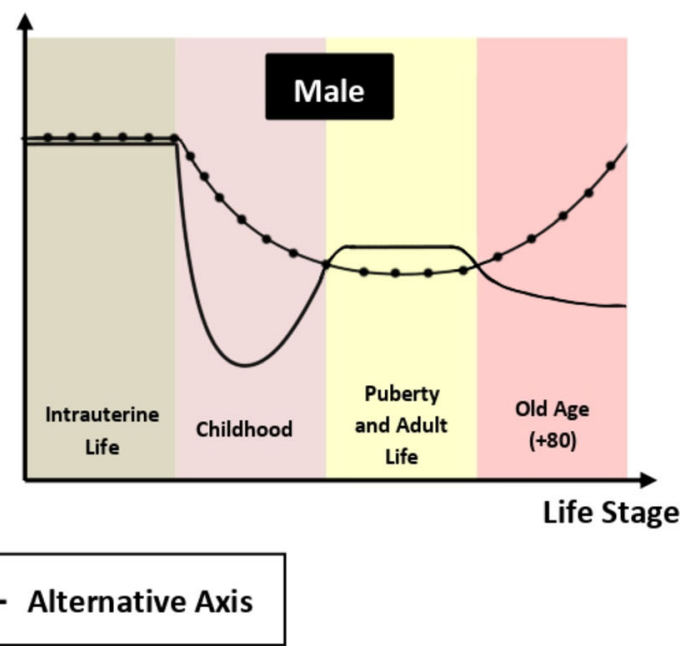

Fig. 3 Dynamic changes of RAS molecules during life span. Legend: There is not enough evidence for RAS molecule variations through life in humans. Most studies are related to animal models and we expand their findings to human physiology. During intrauterine life, molecules of both RAS axes are at the highest levels in the circulation. During childhood, levels of RAS molecules decrease significantly, especially molecules of the alternative RAS axis. After puberty and during adult life, molecules of both RAS axes increase and remain relatively stable. However, during elderliness, the alternative RAS axis becomes less activated, while molecules of the classical RAS axis increase. Male subjects usually have biggest variations of the alternative RAS axis during childhood and elderliness 


\section{Concluding remarks}

The RAAS is crucial for kidney homeostasis. The balance between the classical and alternative RAAS axes is complex and depends on several cascades of events and effector molecules to exert its effects throughout the body. In this regard, RAAS inhibitors have grown in clinical relevance due to the multiplicity of beneficial applications. The role of the RAAS in pediatric kidney diseases has been investigated by several research groups in several different conditions. Their findings corroborate the well-known deleterious effect of ACE/Ang II/ AT1R axis upregulation in worsening disease prognosis. In this regard, stimulation of the alternative axis seems promising for reversing the inflammatory and fibrotic processes common in these conditions. Meanwhile, several new RAAS fragments have been discovered and must be closely analyzed to aid further identification of its escape mechanisms and their pharmacological potential, mainly in cardiovascular and kidney diseases. Although the pathophysiology of COVID-19 remains obscure and requires further study, the RAAS hypothesis may help explain the disease's natural history.

\section{Key summary points}

- Two counter-regulatory axes form the renin-angiotensin-aldosterone system (RAAS): ACE/angiotensin II/AT1 receptor axis and ACE2/angiotensin-(1-7)/Mas receptor axis.

- The binding of angiotensin II to the AT1 receptor leads to vasoconstriction, inflammation, fibrosis, and tissue damage.

- The binding of angiotensin-(1-7) to the Mas receptor results in anti-inflammatory, anti-proliferative, and antifibrogenic actions and organ protection.

- The pathophysiology of COVID-19 infection might rely on a large extent on imbalance of the RAAS.

\section{Multiple-choice questions}

1. Which of the following mechanisms lead to renin release?
a) Increased concentration of sodium in the macula densa
b) Reduced renal blood flow to the afferent arteriole.
c) Alpha adrenergic stimulation
d) Vasoconstriction of the efferent arteriole

2. Binding of Ang II to the AT1 receptor causes which of the following responses?

a) Reduction of endothelial dysfunction

b) Release of nitric oxide and prostaglandins
c) Vasodilation of efferent arteriole
d) Stimulation of renal sodium reabsorption

3. SARS-CoV-2 binding to ACE-2 leads to
a) Viral entry to the target cell
b) Apoptosis of intestinal epithelial cells
c) Systemic inflammation
d) Viral replication

4. Use of ACE inhibitors in hypertensive children with CKD
a) Accelerates loss of kidney function over time
b) Increases the risk of kidney disease progression
c) Decreases the rate of kidney disease progression
d) Worsens blood pressure control

5. Compared with the classical arm of the RAAS, effects of the alternative arm include
a) Increase in proteinuria and reduction of fibrosis
b) Stimulation of fibrosis and increased proteinuria
c) Stimulation of fibrosis and reduction in proteinuria
d) Reduction in fibrosis and decreased proteinuria

Acknowledgments The authors thank Amanda Braga Costa for her assistance with the creation of the figures.

Authors' contributions KL, VAP, and LBC made the literature revision and selection of main articles, defined the topics of this review, and wrote the first draft. ACSS and JTF conceptualized the study, made general supervision, and revised the manuscript. ACSS submitted the final version of the manuscript, which is approved by all authors.

Funding This work was partially supported by Brazilian National Council of Research Development (CNPq - Grant No. 302153/2019-5), Coordination of High Education Level Personnel (CAPES), and Foundation of Research of Minas Gerais (FAPEMIG).

Availability of data and material Not applicable.

\section{Compliance with ethical standards}

Conflict of interest The authors declare that they have no conflict of interest.

Code availability Not applicable.

\section{References}

1. Simões e Silva AC, Teixeira MM (2016) ACE inhibition, ACE2 and angiotensin-(1-7) axis in kidney and cardiac inflammation and fibrosis. Pharmacol Res 107:154-162

2. Basso N, Terragno NA (2001) History about the discovery of the renin-angiotensin system. Hypertension 38:1246-1249 
3. Streeten DH, Anderson GH, Freiberg JM, Dalakos TG (1975) Use of an angiotensin II antagonist (saralasin) in the recognition of "angiotensinogenic" hypertension. N Engl J Med 292:657-662

4. Simões e Silva AC, Flynn JT (2012) The renin-angiotensinaldosterone system in 2011: role in hypertension and chronic kidney disease. Pediatr Nephrol 27:1835-1845

5. Santos RA, Ferreira AJ, Simoes e Silva AC (2008) Angiotenisins. In: Bader M (ed) Cardiovascular hormone systems: from molecular mechanisms to novel therapeutics, 1st edn. Wiley, New York, pp 67-100

6. Santos RA, Brosnihan KB, Chappell MC, Pesquero J, Chernicky CL, Greene LJ, Ferrario CM (1988) Converting enzyme activity and angiotensin metabolism in the dog brainstem. Hypertension 11(2 Pt 2):I153-I157

7. Schiavone MT, Santos RA, Brosnihan KB, Khosla MC, Ferrario CM (1988) Release of vasopressin from the rat hypothalamoneurohypophysial system by angiotensin-(1-7) heptapeptide. Proc Natl Acad Sci U S A 85:4095-4098

8. Campagnole-Santos MJ, Diz DI, Santos RA, Khosla MC, Brosnihan KB, Ferrario CM (1989) Cardiovascular effects of angiotensin-(1-7) injected into the dorsal medulla of rats. Am J Phys 257(1 Pt 2):H324-H329

9. Tipnis SR, Hooper NM, Hyde R, Karran E, Christie G, Turner AJ (2000) A human homolog of angiotensinconverting enzyme cloning and functional expression as a captopril-insensitive carboxypeptidase. J Biol Chem 275: 33238-33243

10. Donoghue M, Hsieh F, Baronas E, Godbout K, Gosselin M, Stagliano N, Donovan M, Woolf B, Robison K, Jeyaseelan R, Breitbart RE, Acton S (2000) A novel angiotensin-converting enzyme-related carboxypeptidase (ACE2) converts angiotensin I to angiotensin 1-9. Circ Res 87:E1-E9

11. Santos RA, Simões e Silva AC, Maric C, Silva DM, Machado RP de Buhr I, Heringer-Walther S, Pinheiro SV, Lopes MT, Bader M, Mendes EP, Lemos VS, Campagnole-Santos MJ, Schultheiss HP, Speth R, Walther T (2003) Angiotensin-(1-7) is an endogenous ligand for the $G$ protein-coupled receptor Mas. Proc Natl Acad Sci U S A 100:8258-8263. https://doi.org/10.1073/pnas.1432869100

12. Rodrigues Prestes TR, Rocha NP, Miranda AS, Teixeira AL, Simões e Silva AC (2017) The Anti-inflammatory potential of ACE2/angiotensin-(1-7)/Mas receptor axis: evidence from basic and clinical research. Curr Drug Targets 18:1301-1313

13. Sparks MA, Crowley SD, Gurley SB, Mirotsou M, Coffman TM (2014) Classical renin-angiotensin system in kidney physiology. Compr Physiol 4:1201-1228. https://doi.org/10.1002/cphy. c130040

14. Patel S, Rauf A, Khan H, Abu-Izneid T (2017) Renin-angiotensinaldosterone (RAAS): the ubiquitous system for homeostasis and pathologies. Biomed Pharmacother 94:317-325

15. Cassis LA, Saye J, Peach MJ (1988) Location and regulation of rat angiotensinogen messenger RNA. Hypertension 11(6 Pt 2):591596

16. Hilgenfeldt $U$ (1988) Half-life of rat angiotensinogen: influence of nephrectomy and lipopolysaccharide stimulation. Mol Cell Endocrinol 56:91-98

17. Campbell DJ (2012) Angiotensin II generation in vivo: does it involve enzymes other than renin and angiotensin-converting enzyme? J Renin Angiotensin Aldosterone Syst 13:314-316

18. Bock HA, Hermle M, Brunner FP, Thiel G (1992) Pressure dependent modulation of renin release in isolated perfused glomeruli. Kidney Int 41:275-280

19. Li XC, Cook JL, Rubera I, Tauc M, Zhang F, Zhuo JL (2011) Intrarenal transfer of an intracellular fluorescent fusion of angiotensin II selectively in proximal tubules increases blood pressure in rats and mice. Am J Physiol Ren Physiol 300:F1076-F1088
20. Celerier J, Cruz A, Lamande N, Gasc JM, Corvol P (2002) Angiotensinogen and its cleaved derivatives inhibit angiogenesis. Hypertension 39:224-228

21. Ehlers MR, Fox EA, Strydom DJ, Riordan JF (1989) Molecular cloning of human testicular angiotensin-converting enzyme: the testis isozyme is identical to the C-terminal half of endothelial angiotensin-converting enzyme. Proc Natl Acad Sci U S A 86: 7741-7745

22. Beldent V, Michaud A, Wei L, Chauvet MT, Corvol P (1993) Proteolytic release of human angiotensin-converting enzyme. Localization of the cleavage site. J Biol Chem 268:26428-26434

23. Margolius HS (1996) Kallikreins and kinins. Molecular characteristics and cellular and tissue responses. Diabetes 45(Suppl 1):S14 S19

24. Husain A, Graham RM (2000) Drugs, enzymes and receptors of the renin-angiotensin system: celebrating a century of discovery. Harwood Academic Publishers, Sydney

25. Murphy TJ, Alexander RW, Griendling KK, Runge MS, Bernstein KE (1991) Isolation of a cDNA encoding the vascular type-1 angiotensin II receptor. Nature 351:233-236

26. Konishi H, Kuroda S, Inada Y, Fujisawa Y (1994) Novel subtype of human angiotensin II type 1 receptor: cDNA cloning and expression. Biochem Biophys Res Commun 199:467-474

27. Timmermans PB, Wong PC, Chiu AT, Herblin WF, Benfield P, Carini DJ, Lee RJ, Wexler RR, Saye JA, Smith RD (1993) Angiotensin II receptors and angiotensin II receptor antagonists. Pharmacol Rev 45:205-251

28. De Gasparo M, Catt K, Inagami T, Wright J, Unger T (2000) International Union of Pharmacology. XXIII. The angiotensin II receptors. Pharmacol Rev 52:415-472

29. Shenoy SK, Lefkowitz RJ (2005) Angiotensin II-stimulated signaling through $\mathrm{G}$ proteins and beta-arrestin. Sci STKE 2005(311): cm14

30. Eguchi S, Numaguchi K, Iwasaki H, Matsumoto T, Yamakawa T, Utsunomiya H, Motley ED, Kawakatsu H, Owada KM, Hirata Y, Marumo F, Inagami T (1998) Calcium-dependent epidermal growth factor receptor transactivation mediates the angiotensin II-induced mitogen-activated protein kinase activation in vascular smooth muscle cells. J Biol Chem 273:8890-8896

31. Qadri F, Culman J, Veltmar A, Maas K, Rascher W, Unger T (1993) Angiotensin II-induced vasopressin release is mediated through alpha- 1 adrenoceptors and angiotensin II AT1 receptors in the supraoptic nucleus. J Pharmacol Exp Ther 267:567-574

32. Yamada K, Iyer SN, Chappell MC, Ganten D, Ferrario CM (1998) Converting enzyme determines plasma clearance of angiotensin(1-7). Hypertension 32:496-502

33. Nguyen MTX, Han J, Ralph DL, Veiras LC, McDonough AA (2015) Short-term nonpressor angiotensin II infusion stimulates sodium transporters in proximal tubule and distal nephron. Phys Rep 3:e12496

34. Yang T, Xu C (2017) Physiology and pathophysiology of the intrarenal renin-angiotensin system: an update. J Am Soc Nephrol 28:1040-1049

35. Forrester SJ, Booz GW, Sigmund CD, Coffman TM, Kawai T, Rizzo V, Scalia R, Eguchi S (2018) Angiotensin II signal transduction: an update on mechanisms of physiology and pathophysiology. Physiol Rev 98:1627-1738

36. Takayanagi T, Forrester SJ, Kawai T, Obama T, Tsuji T, Elliott KJ, Nuti E, Rossello A, Kwok HF, Scalia R, Rizzo V, Eguchi S (2016) Vascular ADAM17 as a novel therapeutic target in mediating cardiovascular hypertrophy and perivascular fibrosis induced by angiotensin II. Hypertension 68:949-955

37. Dange RB, Agarwal D, Masson GS, Vila J, Wilson B, Nair A, Francis J (2014) Central blockade of TLR4 improves cardiac function and attenuates myocardial inflammation in angiotensin II- 
induced hypertension. Cardiovasc Res 103:17-27. https://doi.org/ 10.1093/cvr/cvu067

38. Zhang M, Prosser BL, Bamboye MA, Gondim ANS, Santos CX, Martin D, Ghigo A, Perino A, Brewer AC, Ward CW, Hirsch E, Lederer WJ, Shah AM (2015) Contractile function during angiotensin-II activation: increased nox 2 activity modulates cardiac calcium handling via phospholamban phosphorylation. J Am Coll Cardiol 66:261-272

39. Healey JS, Baranchuk A, Crystal E, Morillo CA, Garfinkle M, Yusuf S, Connolly SJ (2005) Prevention of atrial fibrillation with angiotensin-converting enzyme inhibitors and angiotensin receptor blockers: a meta-analysis. J Am Coll Cardiol 45:1832-1839

40. Lanza K, Perez LG, Costa LB, Cordeiro TM, Palmeira VA, Ribeiro VT, Simões e Silva AC (2020) Covid-19: the renin angiotensin system imbalance hypothesis. Clin Sci 134:1259-1264. https://doi.org/10.1042/CS20200492

41. Kuba K, Imai Y, Penninger JM (2006) Angiotensin-converting enzyme 2 in lung diseases. Curr Opin Pharmacol 6:271-276

42. Sodhi CP, Nguyen J, Yamaguchi Y, Werts AD, Lu P, Ladd MR, Fulton WB, Kovler ML, Wang S, Prindle T Jr, Zhang Y, Lazartigues ED, Holtzman MJ, Alcorn JF, Hackam DJ, Jia H (2019) a dynamic variation of pulmonary ACE2 is required to modulate neutrophilic inflammation in response to pseudomonas aeruginosa lung infection in mice. J Immunol 203:3000-3012

43. Wang J, Chen L, Chen B, Meliton A, Liu SQ, Shi Y, Liu T, Deb DK, Solway J, Li YC (2015) Chronic activation of the reninangiotensin system induces lung fibrosis. Sci Rep 5:15561

44. Rocha NP, Simões e Silva AC, Rodrigues Prestes TR, Feracin V, Machado CA, Ferreira RN, Teixeira AL, Miranda AS (2018) RAS in the central nervous system: potential role in neuropsychiatric disorders. Curr Med Chem 25:3333-3352

45. Saavedra JM (2005) Brain angiotensin II: new developments, unanswered questions and therapeutic opportunities. Cell Mol Neurobiol 25:485-512

46. Kalupahana NS, Massiera F, Quignard-Boulange A, Ailhaud G, Voy BH, Wasserman DH, Moustaid-Moussa N (2012) Overproduction of angiotensinogen from adipose tissue induces adipose inflammation, glucose intolerance, and insulin resistance. Obesity 20:48-56

47. Massiera F, Seydoux J, Geloen A, Quignard-Boulange A, Turban S, Saint-Marc P, Fukamizu A, Negrel R, Ailhaud G, Teboul M (2001) Angiotensinogen-deficient mice exhibit impairment of diet-induced weight gain with alteration in adipose tissue development and increased locomotor activity. Endocrinology 142: 5220-5225

48. Zhou MS, Schulman IH, Zeng Q (2012) Link between the reninangiotensin system and insulin resistance: implications for cardiovascular disease. Vasc Med 17:330-341. https://doi.org/10.1177/ $1358863 X 12450094$

49. Simões e Silva AC, Miranda AS, Rocha NP, Teixeira AL (2017) Renin angiotensin system in liver diseases: friend or foe? World $\mathrm{J}$ Gastroenterol 23:3396-3406

50. Vilas-Boas WW, Ribeiro-Oliveira A, Pereira RM, Ribeiro CR, Almeida J, Nadu AP, Simões e Silva AC, Santos RA (2009) Relationship between angiotensin-(1-7) and angiotensin II correlates with hemodynamic changes in human liver cirrhosis. World $\mathrm{J}$ Gastroenterol 15:2512-2519

51. Pereira RM, Santos RA, Teixeira MM, Leite VH, Costa LP, Costa Dias FL, Barcelos LS, Collares GB, Simões e Silva AC (2007) The renin-angiotensin system in a rat model of hepatic fibrosis: evidence for a protective role of angiotensin-(1-7). J Hepatol 46: 674-681

52. Herath CB, Warner FJ, Lubel JS, Dean RG, Jia Z, Lew RA, Smith AI, Burrell LM, Angus PW (2007) Upregulation of hepatic angiotensin-converting enzyme 2 (ACE2) and angiotensin-(1-7) levels in experimental biliary fibrosis. J Hepatol 47:387-395
53. Jiang F, Yang J, Zhang Y, Dong M, Wang S, Zhang Q, Liu FF, Zhang K, Zhang C (2014) Angiotensin-converting enzyme 2 and angiotensin 1-7: novel therapeutic targets. Nat Rev Cardiol 11: 413-426

54. Domenig O, Manzel A, Grobe N, Konigshausen E, Kaltenecker CC, Kovarik JJ, Stegbauer J, Gurley SB, van Oyen D, Antlanger M, Bader M, Motta-Santos D, Santos RA, Elased KM, Saemann MD, Linker RA, Poglitsch M (2016) Neprilysin is a mediator of alternative renin-angiotensin-system activation in the murine and human kidney. Sci Rep 6:33678

55. Westwood BM, Chappell MC (2012) Divergent pathways for the angiotensin-(1-12) metabolism in the rat circulation and kidney. Peptides 35:190-195

56. Myohanen TT, Garcia-Horsman JA, Tenorio-Laranga J, Mannisto PT (2009) Issues about the physiological functions of prolyl oligopeptidase based on its discordant spatial association with substrates and inconsistencies among mRNA, protein levels, and enzymatic activity. J Histochem Cytochem 57:831-848

57. Munoz MC, Giani JF, Dominici FP (2010) Angiotensin-(1-7) stimulates the phosphorylation of Akt in rat extracardiac tissues in vivo via receptor Mas. Regul Pept 161:1-7. https://doi.org/10. 1016/j.regpep.2010.02.001

58. Zohn IE, Symons M, Chrzanowska-Wodnicka M, Westwick JK, Der CJ (1998) Mas oncogene signaling and transformation require the small GTP-binding protein Rac. Mol Cell Biol 18:1225-1235

59. Alenina N, Bader M, Walther T (2002) Imprinting of the murine MAS protooncogene is restricted to its antisense RNA. Biochem Biophys Res Commun 290:1072-1078

60. Santos SHS (2019) Angiotensin-(1-7): role in the endocrine system. In: Santos RAS (ed) Angiotensin-(1-7): a comprehensive review. Springer International Publishing, pp 153-168

61. Simões e Silva AC, Santos RA (2019) Kidney. In: Santos RA (ed) Angiotensin-(1-7): a comprehensive review. Springer International Publishing, Cham, pp 117-130

62. Vijayaraghavan K, Deedwania P (2011) Renin-angiotensinaldosterone blockade for cardiovascular disease prevention. Cardiol Clin 29:137-156

63. Ferreira AJ, Castro CH, Santos RA (2019) Heart-coronary vessels and cardiomyocytes. In: Santos RAS (ed) Angiotensin-(1-7): a comprehensive review. Springer International Publishing, pp 7381

64. Shenoy V, Ferreira AJ, Qi Y, Fraga-Silva RA, Diez-Freire C, Dooies A, Jun JY, Sriramula S, Mariappan N, Pourang D, Venugopal CS, Francis J, Reudelhuber T, Santos RA, Patel JM, Raizada MK, Katovich MJ (2010) The angiotensin-converting enzyme 2/angiogenesis-(1-7)/Mas axis confers cardiopulmonary protection against lung fibrosis and pulmonary hypertension. Am J Respir Crit Care Med 182:1065-1072

65. Magalhaes GS, Barroso LC, Reis AC, Rodrigues-Machado MG, Gregorio JF, Motta-Santos D, Oliveira AC, Perez DA, Barcelos LS, Teixeira MM, Santos RA, Pinho V, Campagnole-Santos MJ (2018) Angiotensin-(1-7) promotes resolution of eosinophilic inflammation in an experimental model of asthma. Front Immunol 9:58

66. Guimaraes PS, Santiago NM, Xavier CH, Velloso EP, Fontes MA, Santos RA, Campagnole-Santos MJ (2012) Chronic infusion of angiotensin-(1-7) into the lateral ventricle of the brain attenuates hypertension in DOCA-salt rats. Am J Physiol Heart Circ Physiol 303:H393-H400

67. Campagnole-Santos MJ, Gironacci MM, Fontes MA (2019) Brain. In: Santos RA (ed) Angiotensin-(1-7): a comprehensive review. Springer International Publishing, Cham, pp 55-71

68. Guimaraes PS, Oliveira MF, Braga JF, Nadu AP, Schreihofer A, Santos RA, Campagnole-Santos MJ (2014) Increasing angiotensin-(1-7) levels in the brain attenuates metabolic syndrome-related risks in fructose-fed rats. Hypertension 63:1078-1085 
69. Mecca AP, Regenhardt RW, O'Connor TE, Joseph JP, Raizada MK, Katovich MJ, Sumners C (2011) Cerebroprotection by angiotensin-(1-7) in endothelin-1-induced ischaemic stroke. Exp Physiol 96:1084-1096

70. Santos SH, Fernandes LR, Mario EG, Ferreira AV, Porto LC, Alvarez-Leite JI, Botion LM, Bader M, Alenina N, Santos RA (2008) Mas deficiency in FVB/N mice produces marked changes in lipid and glycemic metabolism. Diabetes 57:340-347

71. Schön M, Kovaničová Z, Košutzká Z, Nemec M, Tomková M, Jacková L, Máderová D, Slobodová L, Valkovič P, Ukropec J (2019) Effects of running on adiponectin, insulin and cytokines in cerebrospinal fluid in healthy young individuals. Sci Rep 9:111

72. Lautner RQ, Villela DC, Fraga-Silva RA, Silva N, Verano-Braga T, Costa-Fraga F, Jankowski J, Jankowski V, Sousa F, Alzamora A, Soares E, Barbosa C, Kjeldsen F, Oliveira A, Braga J, Savergnini S, Maia G, Peluso AB, Passos-Silva D, Ferreira A, Alves F, Martins A, Raizada M, Paula R, Motta-Santos D, Klempin F, Pimenta A, Alenina N, Sinisterra R, Bader M, Campagnole-Santos MJ, Santos RA (2013) Discovery and characterization of alamandine: a novel component of the reninangiotensin system. Circ Res 112:1104-1111

73. Annweiler C, Cao Z, Wu Y, Faucon E, Mouhat S, Kovacic H, Sabatier J-M (2020) Counter-regulatory 'renin-angiotensin' system-based candidate drugs to treat COVID-19 diseases in SARS-CoV-2-infected patients. Curr Drug Targets - Infect Disord. https://doi.org/10.2174/1871526520666200518073329

74. Schleifenbaum J (2019) Alamandine and its receptor MrgD pair up to join the protective arm of the renin-angiotensin system. Front Med 6:107

75. Jesus ICG, Scalzo S, Alves F, Marques K, Rocha-Resende C, Bader M, Santos RA, Guatimosim S (2018) Alamandine acts via MrgD to induce AMPK/NO activation against ANG II hypertrophy in cardiomyocytes. Am J Phys Cell Phys 314:C702-C711

76. Yugandhar VG, Clark MA (2013) Angiotensin III: a physiological relevant peptide of the renin angiotensin system. Peptides 46:2632

77. Park BM, Cha SA, Lee SH, Kim SH (2016) Angiotensin IV protects cardiac reperfusion injury by inhibiting apoptosis and inflammation via AT4R in rats. Peptides 79:66-74

78. Martínez-Martos JM, del Pilar Carrera-González M, Dueñas B, Mayas MD, García MJ, Ramírez-Expósito MJ (2011) Renin angiotensin system-regulating aminopeptidase activities in serum of pre- and postmenopausal women with breast cancer. Breast 20: 444-447

79. Padia SH, Howell NL, Siragy HM, Carey RM (2006) Renal angiotensin type 2 receptors mediate natriuresis via angiotensin III in the angiotensin II type 1 receptor-blocked rat. Hypertension 47:537544

80. Wright JW, Krebs LT, Stobb JW, Harding JW (1995) The angiotensin IV system: functional implications. Front Neuroendocrinol $16: 23-52$

81. Lochard N, Thibault G, Silversides DW, Touyz RM, Reudelhuber TL (2004) Chronic production of angiotensin IV in the brain leads to hypertension that is reversible with an angiotensin II AT1 receptor antagonist. Circ Res 94:1451-1457

82. Vinh A, Widdop RE, Drummond GR, Gaspari TA (2008) Chronic angiotensin IV treatment reverses endothelial dysfunction in ApoE-deficient mice. Cardiovasc Res 77:178-187

83. Albiston AL, McDowall SG, Matsacos D, Sim P, Clune E, Mustafa T, Lee J, Mendelsohn FA, Simpson RJ, Connolly LM, Chai SY (2001) Evidence that the angiotensin IV (AT(4)) receptor is the enzyme insulin-regulated aminopeptidase. J Biol Chem 276: 48623-48626

84. Rice GI, Thomas DA, Grant PJ, Turner AJ, Hooper NM (2004) Evaluation of angiotensin-converting enzyme (ACE), its homologue ACE2 and neprilysin in angiotensin peptide metabolism. Biochem J 383:45-51

85. Ocaranza MP, Moya J, Barrientos V, Alzamora R, Hevia D, Morales C, Pinto M, Escudero N, Garcia L, Novoa U, Ayala P, Diaz-Araya G, Godoy I, Chiong M, Lavandero S, Jalil JE, Michea L (2014) Angiotensin-(1-9) reverses experimental hypertension and cardiovascular damage by inhibition of the angiotensin converting enzyme/Ang II axis. J Hypertens 32:771-783

86. Sotomayor-Flores C, Rivera-Mejias P, Vasquez-Trincado C, Lopez-Crisosto C, Morales PE, Pennanen C, Polakovicova I, Aliaga-Tobar V, Garcia L, Roa JC, Rothermel BA, MaracajaCoutinho V, Ho-Xuan H, Meister G, Chiong M, Ocaranza MP, Corvalan AH, Parra V, Lavandero S (2020) Angiotensin-(1-9) prevents cardiomyocyte hypertrophy by controlling mitochondrial dynamics via miR-129-3p/PKIA pathway. Cell Death Differ. https://doi.org/10.1038/s41418-020-0522-3

87. Cha SA, Park BM, Kim SH (2018) Angiotensin-(1-9) ameliorates pulmonary arterial hypertension via angiotensin type II receptor. Korean J Physiol Pharmacol 22:447-456

88. Nagata S, Kato J, Sasaki K, Minamino N, Eto T, Kitamura K (2006) Isolation and identification of proangiotensin-12, a possible component of the renin-angiotensin system. Biochem Biophys Res Commun 350:1026-1031

89. Ahmad S, Varagic J, Groban L, Dell'Italia LJ, Nagata S, Kon ND, Ferrario CM (2014) Angiotensin-(1-12): a chymase-mediated cellular angiotensin II substrate. Curr Hypertens Rep 16:429

90. Jankowski V, Vanholder R, van der Giet M, Tolle M, Karadogan S, Gobom J, Furkert J, Oksche A, Krause E, Tran TN, Tepel M, Schuchardt M, Schluter H, Wiedon A, Beyermann M, Bader M, Todiras M, Zidek W, Jankowski J (2007) Mass-spectrometric identification of a novel angiotensin peptide in human plasma. Arterioscler Thromb Vasc Biol 27:297-302

91. Hrenak J, Paulis L, Simko F (2016) Angiotensin A/alamandine/ MrgD axis: another clue to understanding cardiovascular pathophysiology. Int J Mol Sci 17:1098

92. Simões e Silva AC, Diniz JS, Regueira Filho A, Santos RA (2004) The renin angiotensin system in childhood hypertension: selective increase of angiotensin-(1-7) in essential hypertension. J Pediatr 145:93-98

93. Flynn J (2013) The changing face of pediatric hypertension in the era of the childhood obesity epidemic. Pediatr Nephrol 28:1059 1066

94. South AM, Nixon PA, Chappell MC, Diz DI, Russell GB, Shaltout HA, O'Shea TM, Washburn LK (2019) Obesity is associated with higher blood pressure and higher levels of angiotensin II but lower angiotensin-(1-7) in adolescents born preterm. J Pediatr 205:55-60

95. Khatri M, Zitovsky J, Lee D, Nayyar K, Fazzari M, Grant C (2020) The association between serum chloride levels and chronic kidney disease progression: a cohort study. BMC Nephrol 21:165

96. Burnier M (2020) Increasing potassium intake to prevent kidney damage: a new population strategy? Kidney Int 98:59-61

97. South AM, Shaltout HA, Washburn LK, Hendricks AS, Diz DI, Chappell MC (2019) Fetal programming and the angiotensin-(1-7) axis: a review of the experimental and clinical data. Clin Sci 133: $55-74$

98. Pinheiro SV, Ferreira AJ, Kitten GT, Silveira KD, da Silva DA, Santos SH, Gava E, Castro CH, Magalhaes JA, da Mota RK, Botelho-Santos GA, Bader M, Alenina N, Santos RA, Simões e Silva AC (2009) Genetic deletion of the angiotensin-(1-7) receptor Mas leads to glomerular hyperfiltration and microalbuminuria. Kidney Int 75:1184-1193

99. Silveira KD, Barroso LC, Vieira AT, Cisalpino D, Lima CX, Bader M, Arantes RM, Santos RA, Simões e Silva AC, Teixeira MM (2013) Beneficial effects of the activation of the angiotensin- 
(1-7) MAS receptor in a murine model of adriamycin-induced nephropathy. PLoS One 8:e66082

100. Silva-Filha R, Pinheiro SV, Cordeiro TM, Feracin V, Vieira EL, Miranda AS, Simões e Silva AC (2019) Evidence for a role of angiotensin converting enzyme 2 in proteinuria of idiopathic nephrotic syndrome. Biosci Rep 39:BSR20181361

101. Nadarajah R, Milagres R, Dilauro M, Gutsol A, Xiao F, Zimpelmann J, Kennedy C, Wysocki J, Batlle D, Burns KD (2012) Podocyte-specific overexpression of human angiotensinconverting enzyme 2 attenuates diabetic nephropathy in mice. Kidney Int 82:292-303

102. Ng HY, Yisireyili M, Saito S, Lee CT, Adelibieke Y, Nishijima F, Niwa T (2014) Indoxyl sulfate downregulates expression of Mas receptor via OAT3/AhR/Stat3 pathway in proximal tubular cells. PLoS One 9:e91517

103. Baum M (2010) Role of the kidney in the prenatal and early postnatal programming of hypertension. Am J Physiol Ren Physiol 298:F235-F247

104. Zhu Y, Zuo N, Li B, Xiong Y, Chen H, He H, Sun Z, Hu S, Cheng H, Ao Y, Wang H (2018) The expressional disorder of the renal RAS mediates nephrotic syndrome of male rat offspring induced by prenatal ethanol exposure. Toxicology 400:9-19

105. Simões e Silva AC, Valerio FC, Vasconcelos MA, Miranda DM, Oliveira EA (2013) Interactions between cytokines, congenital anomalies of kidney and urinary tract and chronic kidney disease. Clin Dev Immunol 2013:597920

106. Rocha NP, Bastos FM, Vieira ELM, Prestes TRR, Silveira KDD, Teixeira MM, Simões SAC (2019) The protective arm of the renin-angiotensin system may counteract the intense inflammatory process in fetuses with posterior urethral valves. J Pediatr 95:328333

107. Flynn JT, Mitsnefes M, Pierce C, Cole SR, Parekh RS, Furth SL, Warady BA (2008) Blood pressure in children with chronic kidney disease: a report from the Chronic Kidney Disease in Children study. Hypertension 52:631-637

108. Shatat IF, Flynn JT (2005) Hypertension in children with chronic kidney disease. Adv Chronic Kidney Dis 12:378-384

109. Simões e Silva AC, Diniz JC, Pereira RM, Pinheiro SV, Santos RA (2006) Circulating renin angiotensin system in childhood chronic renal failure: marked increase of angiotensin-(1-7) in end-stage renal disease. Pediatr Res 60:734-739

110. Sun CY, Chang SC, Wu MS (2012) Uremic toxins induce kidney fibrosis by activating intrarenal renin-angiotensin-aldosterone system associated epithelial-to-mesenchymal transition. PLoS One 7: e34026

111. Liu WC, Tomino Y, Lu KC (2018) impacts of indoxyl sulfate and p-cresol sulfate on chronic kidney disease and mitigating effects of ast-120. Toxins (Basel) 10:367

112. Ma L, Han C, Peng T, Li N, Zhang B, Zhen X, Yang X (2016) Ang-(1-7) inhibited mitochondrial fission in high-glucose-induced podocytes by upregulation of miR-30a and downregulation of Drp1 and p53. J Chin Med Assoc 79:597-604

113. Ali Q, Patel S, Hussain T (2015) Angiotensin AT2 receptor agonist prevents salt-sensitive hypertension in obese Zucker rats. Am J Physiol Ren Physiol 308:F1379-F1385

114. Basile DP, Anderson MD, Sutton TA (2011) Pathophysiology of acute kidney injury. Compr Physiol 2:1303-1353

115. Barroso LC, Silveira KD, Lima CX, Borges V, Bader M, Rachid M, Santos RAS, Souza DG, Simões E, Silva AC, Teixeira MM (2012) Renoprotective effects of AVE0991, a nonpeptide Mas receptor agonist, in experimental acute renal injury. Int $\mathrm{J}$ Hypertens 2012:808726

116. Ribeiro-Oliveira A Jr, Nogueira AI, Pereira RM, Boas WWV, dos Santos RAS, Simões e Silva AC (2008) The renin-angiotensin system and diabetes: an update. Vasc Health Risk Manag 4:787803
117. Alves MT, Chaves ACS, Almeida APM, Simões E, Silva AC, Araújo SA, Mota APL, Dos Mares-Guia TR, Fernandes AP, Gomes KB (2020) Anti-inflammatory effects of C-peptide on kidney of type 1 diabetes mellitus animal model. Mol Biol Rep 47: 721-726

118. Bangalore S, Fakheri R, Toklu B, Messerli FH (2016) Diabetes mellitus as a compelling indication for use of renin angiotensin system blockers: systematic review and meta-analysis of randomized trials. BMJ 352:i438

119. Mori J, Patel VB, Ramprasath T, Alrob OA, DesAulniers J, Scholey JW, Lopaschuk GD, Oudit GY (2014) Angiotensin 1-7 mediates renoprotection against diabetic nephropathy by reducing oxidative stress, inflammation, and lipotoxicity. Am J Physiol Ren Physiol 306:F812-F821

120. Belisário AR, da Silva AA, Silva CV, de Souza LM, Wakabayashi EA, Araujo SA, Simões e Silva AC (2019) Sickle cell disease nephropathy: an update on risk factors and potential biomarkers in pediatric patients. Biomark Med 13:965-985

121. Belisário AR, Vieira ELM, Almeida JA, Mendes FG, Miranda AS, Rezende PV, Viana MB, Simões E, Silva AC (2020) Evidence for interactions between inflammatory markers and renin-angiotensin system molecules in the occurrence of albuminuria in children with sickle cell anemia. Cytokine 125:154800

122. Belisário AR, Almeida JA, Mendes FG, da Silva DMM, Planes W, Rezende PV, Silva CM, Brito AC, Sales RR, Viana MB, Simões E, Silva AC (2020) Prevalence and risk factors for albuminuria and glomerular hyperfiltration in a large cohort of children with sickle cell anemia. Am J Hematol 95:E125-E128

123. Belisário AR, Vieira ÉLM, de Almeida JA, Mendes FG, Miranda AS, Rezende PV, Viana MB, Simões E, Silva AC (2019) Low urinary levels of angiotensin-converting enzyme 2 may contribute to albuminuria in children with sickle cell anaemia. Brit J Hematol 185:190-193

124. Pinheiro SVB, Dias RF, Fabiano RCG, Araujo SA, Simões e Silva AC (2019) Pediatric lupus nephritis. Braz J Nephrol 41:252-265

125. Teplitsky V, Shoenfeld Y, Tanay A (2006) The renin-angiotensin system in lupus: physiology, genes and practice, in animals and humans. Lupus 15:319-325

126. De Albuquerque DA, Saxena V, Adams DE, Boivin GP, Brunner HI, Witte DP, Singh RR (2004) An ACE inhibitor reduces Th2 cytokines and TGF- $\beta 1$ and TGF- $\beta 2$ isoforms in murine lupus nephritis. Kidney Int 65:846-859

127. Zhou P, Yang XL, Wang X, Hu B, Zhang L, Zhang W, Si HR, Zhu Y, Li B, Huang CL, Chen HD, Chen J, Luo Y, Guo H, Jiang RD, Liu MQ, Chen Y, Shen XR, Wang X, Zheng XS, Zhao K, Chen QJ, Deng F, Liu LL, Yan B, Zhan FX, Wang YY, Xiao GF, Shi ZL (2020) A pneumonia outbreak associated with a new coronavirus of probable bat origin. Nature 579:270-273

128. South AM, Brady TM, Flynn JT (2020) ACE2, COVID-19, and $\mathrm{ACE}$ inhibitor and ARB use during the pandemic: the pediatric perspective. Hypertension 76:16-22

129. Epidemiology Working Group of NCIP Epidemic Response, Chinese Center for Disease Control and Prevention (2020) The epidemiological characteristics of an outbreak of 2019 novel coronavirus diseases (COVID-19) in China. Zhonghua Liu Xing Bing Xue Za Zhi 41:145-151

130. Liu W, Zhang Q, Chen J, Xiang R, Song H, Shu S, Chen L, Liang L, Zhou J, You L, Wu P, Zhang B, Lu Y, Xia L, Huang L, Yang Y, Liu F, Semple MG, Cowling BJ, Lan K, Sun Z, Yu H, Liu Y (2020) Detection of Covid-19 in children in early January 2020 in Wuhan, China. N Engl J Med 382:1370-1371

131. Task force COVID-19 del Dipartimento Malattie Infettive e Servizio di Informatica, Instituto Superiore di Sanita (2020) Epidemia COVID-19. Aggiornamento Nazionale: 23 aprile 2020 Report, Available from https://www.epicentro.iss.it/ 
coronavirus/bollettino/Bollettino-sorveglianza-integrata-COVID19 23-aprile-2020.pdf. Accessed 04 June 2020

132. Wu Z, McGoogan JM (2020) Characteristics of and important lessons from the coronavirus disease 2019 (COVID-19) outbreak in China: summary of a report of 72314 cases from the Chinese Center for Disease Control and Prevention. JAMA 323:12391242

133. (2020) Coronavirus Disease 2019 in Children - United States, February 12-April 2, 2020. MMWR Morb Mortal Wkly Report 69:422-426. https://doi.org/10.15585/mmwr.mm6914e4

134. Heinonen S, Rodriguez-Fernandez R, Diaz A, Rodriguez-Pastor SO, Ramilo O, Mejias A (2019) Infant immune response to respiratory viral infections. Immunol Allergy Clin 39:361-376

135. Yan R, Zhang Y, Li Y, Xia L, Guo Y, Zhou Q (2020) Structural basis for the recognition of SARS-CoV-2 by full-length human ACE2. Science 367:1444-1448

136. Rodriguez-Morales AJ, Cardona-Ospina JA, Gutiérrez-Ocampo E, Villamizar-Peña R, Holguin-Rivera Y, Escalera-Antezana JP, Alvarado-Arnez LE, Bonilla-Aldana DK, Franco-Paredes C, Henao-Martinez AF, Paniz-Mondolfi A, Lagos-Grisales GJ, Ramírez-Vallejo E, Suárez JA, Zambrano LI, Villamil-Gómez WE, Balbin-Ramon GJ, Rabaan AA, Harapan H, Dhama K, Nishiura H, Kataoka H, Ahmad T, Sah R, Latin American Network of Coronavirus Disease 2019-COVID-19 Research (LANCOVID-19) (2020) Clinical, laboratory and imaging features of COVID-19: a systematic review and meta-analysis. Travel Med Infec Dis 34:101623

137. Gattinoni L, Coppola S, Cressoni M, Busana M, Rossi S, Chiumello D (2020) COVID-19 does not lead to a "typical" acute respiratory distress syndrome. Am J Resp Critic Care Med 201: 1299-1300

138. Pedersen SF, Ho YC (2020) SARS-CoV-2: a storm is raging. J Clin Invest 130:2202-2205
139. Channappanavar R, Perlman S (2017) Pathogenic human coronavirus infections: causes and consequences of cytokine storm and immunopathology. Semin Immunopathol 39:529-539

140. Vinturache AE, Smith FG (2014) Do angiotensin type 2 receptors modulate haemodynamic effects of type 1 receptors in conscious newborn lambs? J Renin Angiotensin Aldosterone Syst 15:450-457

141. Sampson AK, Moritz KM, Denton KM (2012) Postnatal ontogeny of angiotensin receptors and ACE2 in male and female rats. Gender Med 9:21-32

142. Bunyavanich S, Do A, Vicencio A (2020) Nasal gene expression of angiotensin-converting enzyme 2 in children and adults. JAMA 323:2427-2429. https://doi.org/10.1001/jama.2020.8707

143. Silva-Antonialli MM, Tostes RC, Fernandes L, Fior-Chadi DR, Akamine EH, Carvalho MHC, Nigro D (2004) A lower ratio of AT1/AT2 receptors of angiotensin II is found in female than in male spontaneously hypertensive rats. Cardiovasc Res 62:587-593

144. Hinojosa-Laborde C, Craig T, Zheng W, Ji H, Haywood JR, Sandberg K (2004) Ovariectomy augments hypertension in aging female Dahl salt-sensitive rats. Hypertension 44:405-409

145. Sullivan JC, Rodriguez-Miguelez P, Zimmerman MA, Harris RA (2015) Differences in angiotensin (1-7) between men and women. Am J Physiol Heart Circ Physiol 308:H1171-H1176

\section{Answers to study questions:}

1. b; 2. d; 3. a; 4. c; 5. d

Publisher's note Springer Nature remains neutral with regard to jurisdictional claims in published maps and institutional affiliations. 